\title{
Total wave power absorption by a multi-float wave energy converter and a semi-submersible wind platform with a fast far field model for arrays
}

\author{
Peter Stansby ${ }^{1}\left[\right.$ Efrain Carpintero Moreno $^{2} \cdot$ Sam $_{\text {Draycott }}{ }^{1} \cdot$ Tim Stallard $^{1}$
}

Received: 2 June 2021 / Accepted: 24 September 2021 / Published online: 19 October 2021

(c) The Author(s) 2021

\begin{abstract}
Wave energy converters absorb wave power by mechanical damping for conversion into electricity and multi-float systems may have high capture widths. The kinetic energy of the floats causes waves to be radiated, generating radiation damping. The total wave power absorbed is thus due to mechanical and radiation damping. A floating offshore wind turbine platform also responds dynamically and damping plates are generally employed on semi-submersible configurations to reduce motion, generating substantial drag which absorbs additional wave power. Total wave power absorption is analysed here by linear wave diffraction-radiation-drag models for a multi-float wave energy converter and an idealised wind turbine platform, with response and mechanical power in the wave energy case compared with wave basin experiments, including some directional spread wave cases, and accelerations compared in the wind platform case. The total power absorption defined by capture width is input into a far field array model with directional wave spreading. Wave power transmission due a typical wind turbine array is only reduced slightly (less than $5 \%$ for a $10 \times 10$ platform array) but may be reduced significantly by rows of wave energy converters (by up to about 50\%).
\end{abstract}

Keywords Multi-float wave energy converter - Semi-sub wind platform - Total wave power absorption $\cdot$ Radiated wave power · Array model

\section{Introduction}

Floating platforms for offshore renewable energy are becoming established for wind energy and are in early stage development for wave energy. We consider here total wave power absorption by platforms necessary to determine wave fields due to arrays, comprising wind or wave farms.

Offshore wind farms are expanding rapidly in many parts of the world. Most platforms to date (2021) have fixed foundations of monopile or jacket structure form, suitable for relatively shallow water, less than about $30 \mathrm{~m}$ deep. Floating foundations or platforms are required for deeper water, markedly increasing the available energy resource. Offshore wind speeds are also higher and less intermittent

Peter Stansby

p.k.stansby@manchester.ac.uk

1 School of Engineering, University of Manchester, Manchester M13 9PL, UK

2 Department of Civil Engineering, Ghent University, 9000 Ghent, Belgium than onshore or nearshore. However, floating platform design is less mature than for fixed platforms with several configurations under consideration, including semi-submersible, spar, tension-leg, barge types and hybrids, see reviews in Koo et al. (2014), Carbon Trust (2015), Leimeister et al. (2018) and design criteria in DNVGL (2019). As floating wind platforms are developed, economic and operational advantages over fixed platforms may become apparent in shallower as well as deeper water.

The influence of wind platforms on the regional wave conditions has received little attention. For fixed platforms, monopiles of about 4-5 m diameter will cause negligible wave diffraction and jacket structures even less. For floating platforms, submerged components are of similar size but they now respond dynamically due to wave action. Power from the onset wave is converted into kinetic energy of the platform, which is in turn converted into radiated wave power, absorbing power from the wave field. Wave power absorption due to radiation damping appears not to have been considered to date and measurement is certainly difficult. However, calculation through a computational model is rel- 
atively straightforward. This is one aim of this paper based on an idealised semi-submersible wind platform which has been studied experimentally and by linear diffraction modelling (Stansby et al. 2019).

Floating wave energy platforms are intended to convert wave power into mechanical energy and then electricity. There have been many concepts, e.g. Falcão (2010), Babarit et al. (2012), without convergence of design, but it is becoming apparent that multi-float systems with multiple PTOs may have capacity similar to wind turbines in some locations, (Stansby et al. 2017; Carpintero Moreno and Stansby 2019). Again wave power is converted into platform kinetic energy as well as mechanical energy, absorbing power due to radiation damping from the incoming waves. It is well known that, for the classical case of the point absorber resonating at maximum efficiency in regular waves, the mechanical power is equal to the radiated power (Falnes 2002). To determine wave power propagation through an array, the total wave power absorption by each platform (due radiation as well as mechanical damping and possibly small drag damping) is required. Another aim is thus to evaluate total wave power absorption as a capture width for multi-float wave energy systems; M4 is chosen which has been studied experimentally and computationally (Stansby et al. 2017; Carpintero Moreno and Stansby 2019). There has been limited experimental investigation with directional spread waves and some computational modelling is presented here.

Combining wave energy conversion by arrays with coastal protection has been considered previously, e.g. Abanades et al. (2015), Rodriguez-Delgado et al. (2019), Bergillos et al. (2020), while the effect of floating wind platform arrays appears not to have been considered. It should be noted that the objectives for wave energy and wind platforms are different; the motion of a wind platform should be as small as possible to support the turbine while the wave energy platform needs to respond optimally for power conversion. For wind platform arrays, wave power absorption is thus a secondary benefit. If total wave power absorption by wave energy converters (WECs) is significant there could also be benefit in using arrays or rows of WECs to reduce wave power transmitted to floating (or fixed) wind farms.

The prediction of wave power absorption (and mechanical conversion) in arrays is complicated by radiated waves from different platforms interacting with the incoming wave field. However some analysis on clusters of point absorbers is relevant here (Göteman et al. 2015). In regular waves, it was shown that radiated wave amplitudes have decayed to less than $4 \%$ over a distance of about 5 wave lengths as radiated waves from different point absorbers have different phase. In irregular waves with frequency components also of different phase, this will be further reduced, and directionally spread waves will reduce this again, e.g. Weller et al. (2010). A cluster of point absorbers is hydrodynamically similar to a multi-float WEC, such as M4, and a multi-float semi-sub wind platform. Typically semi-sub platforms have 3 or 4 columns and the one we consider here has 4 columns. In this paper, we propose a far field wave propagation model for arrays considering total power absorbed without far field radiated effects which are expected to be negligible. The far field model is for directional spread waves and assumes the onset wave power to be uniform in constant depth, providing a fast model suitable for evaluation of many array configurations. Previous coastal wave propagation modelling has used a regional spectral wave model such as SWAN with mechanical power absorption represented as a sink term, e.g. Chang et al. (2016), McNatt et al. (2020).

The remainder of the paper is laid out as follows. Section 2 describes the platform configurations. The linear diffraction/radiation/drag model follows in Sect. 3, then the modification for directional waves in Sect. 4. The far field wave power array model is presented in Sect. 5. Results for response and capture width follow in Sect. 6, comparing with experiment where possible, estimating total capture width due to mechanical and radiation damping for the multi-float wave energy converters and radiation and drag damping for the semi-sub wind platform. Results for wave propagation through rows of wave energy converters and an array of wind floaters are then presented. These are discussed in Sect. 7 and some conclusions are drawn in Sect. 8.

\section{Wave energy conversion and wind platform configurations}

The multi-float wave energy system M4 tested has six floats (Carpintero Moreno and Stansby 2019), with one bow float and three mid-floats in an effectively rigid frame, and two stern floats connected to the two outer mid-floats by beams with hinges above the mid-float for power take-off (PTO) due to relative rotation, as shown in Fig. 1a. This configuration is termed 132. The mass distribution is given in Table 3. This is modelled and a 134 configuration is also modelled with four sterns floats and four PTOs, with the same characteristics as for the 132 configuration. The wind platform is created by removing the stern floats and beams and replacing the bow and mid-floats with cylindrical floats with a flat base and damping plates, as shown in Fig. 1b. The wind turbine and column mass and inertia of the NREL $5 \mathrm{MW}$ wind turbine (Jonkman et al. 2009) are represented by a mass at the hub position. The mass distribution is given in Table 4 .

Figure 2 shows the elevations. The upwards kink in the stern beam in Fig. 2a is to avoid clashing on the mid-float deck in extreme conditions. Also, the PTO in the form of a simple pneumatic damper is positioned for convenience of attachment; at full scale, it would be hinged just above deck level and the mast above hinge level would not be necessary. 
Fig. 1 General configurations: a the 132 wave energy converter platform M4 with beams from the stern floats hinged above mid-floats. b The 4-float wind turbine configuration with mass at the hub to represents the wind turbine mass/inertia distribution

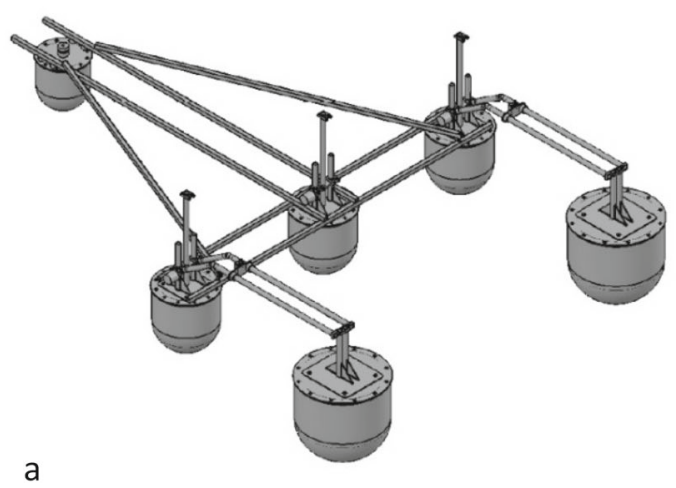

b
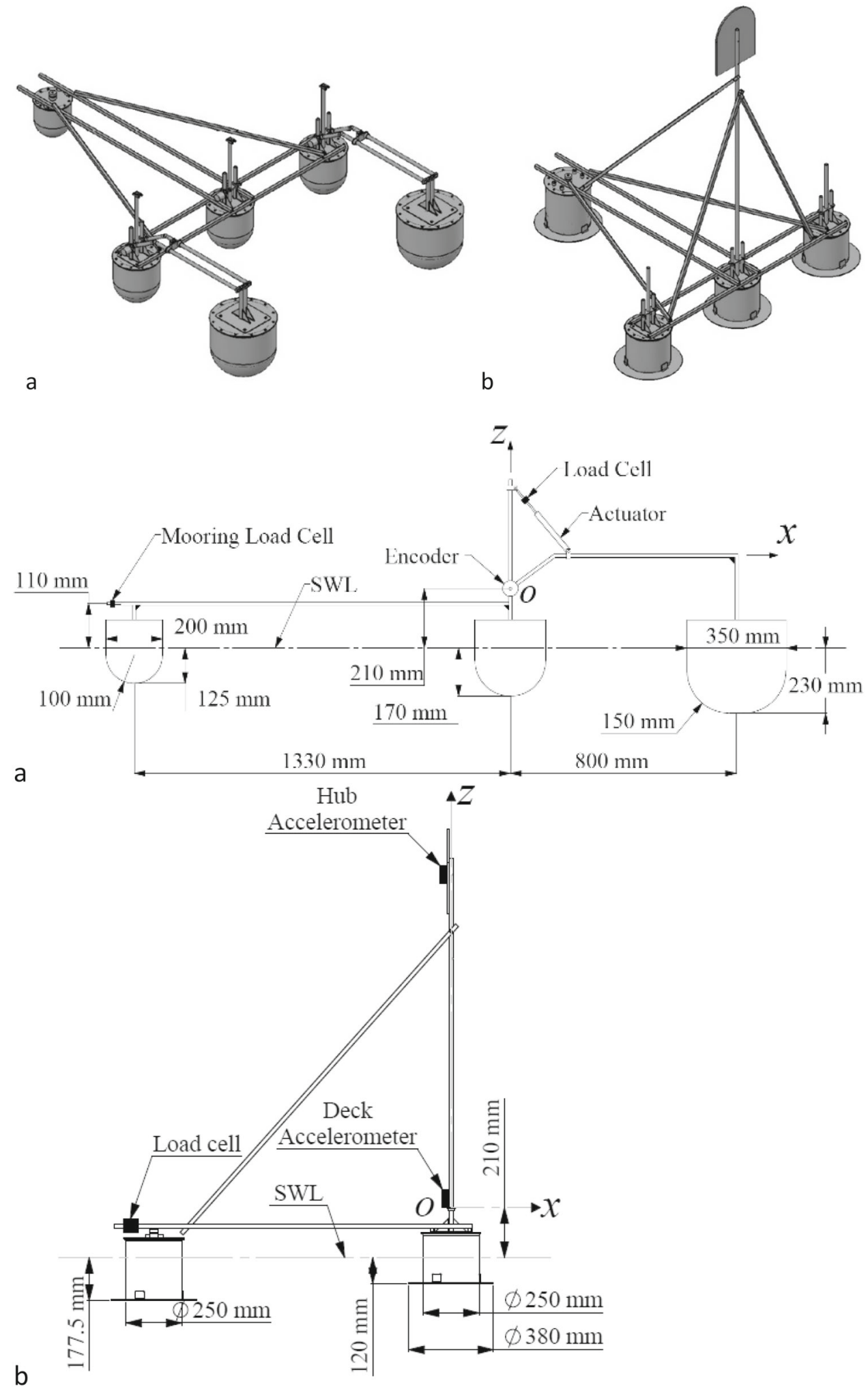

Fig. 2 Side elevations with dimensions and reference position $\mathrm{O}$, showing $x, z$ axes with the $y$ axis normal to the vertical plane: a 132 wave energy platform M4; $\mathbf{b}$ wind turbine platform
The inclined member in Fig. $2 b$ is to maintain rigidity of the turbine mass support. Figure 3 shows the plan dimensions and Fig. 4 snapshots of videos during wave basin testing.

\section{Mathematical formulation and model}

The multi-float time-domain formulation applies to both the WEC M4 and the wind turbine platform. The wind turbine 

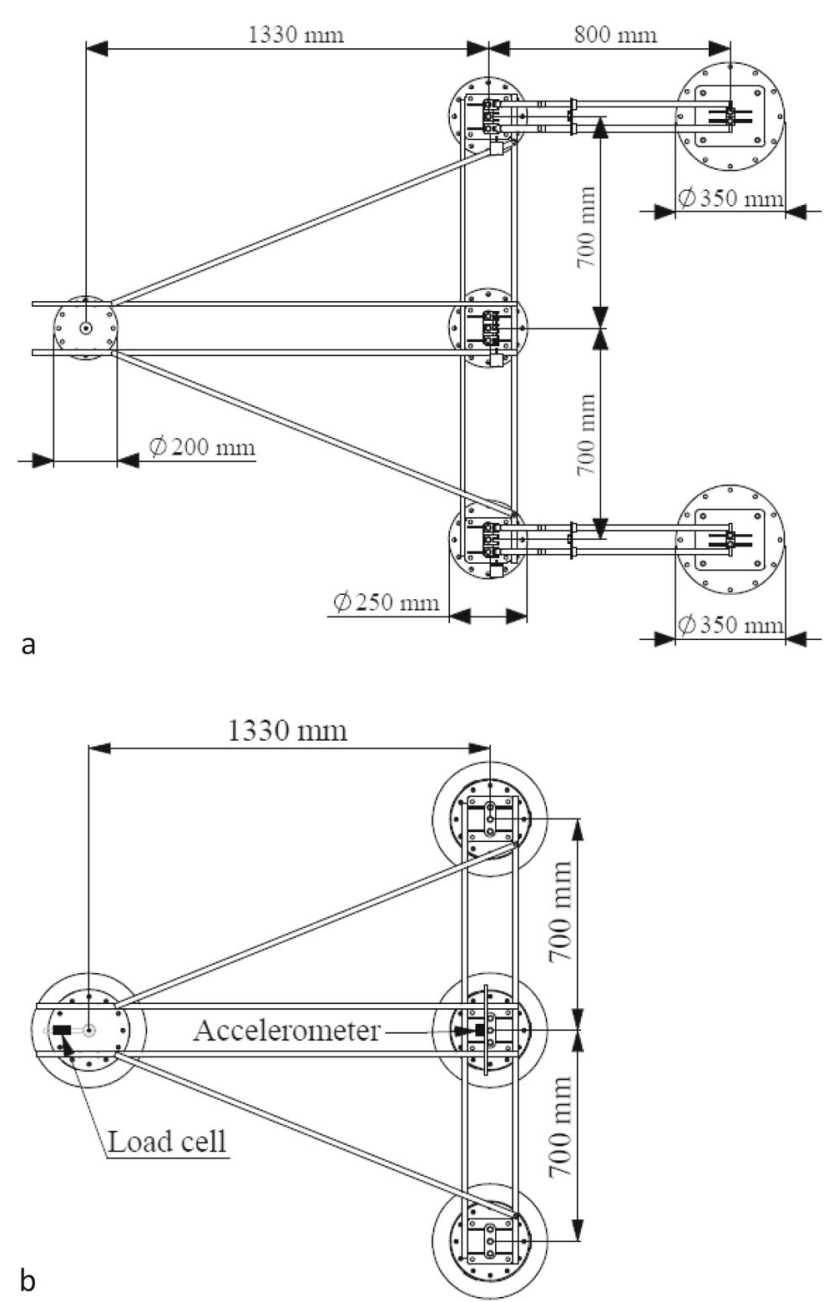

Fig. 3 Plan views: a 32 wave energy platform M4; b wind turbine platform.

platform has no hydrodynamic power take-off, but has additional turbine and drag forces. A general form based on linear hydrodynamics is presented. The hydrodynamic forces are due to linear wave excitation or diffraction, added mass, radiation damping, restoring, drag and mooring forces. Excitation, added mass and radiation damping are defined using WAMIT coefficients (Lee and Newman 2013), using Cummins (1962) method for irregular waves. The standard form of the uni-directional JONSWAP wave spectrum will be used. The model is basically that presented in Stansby and Carpin-
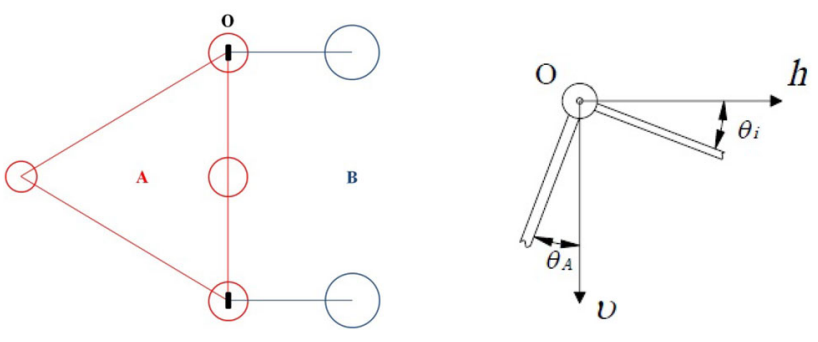

Fig. 5 Plan view of 132 WEC configuration with body A (bow and midfloats in red) and body B (two stern floats in black) with hinge $\mathrm{O}$ shown as solid line and on the right hand side notation $h, v$ and $\theta$ relative to $\mathrm{O}$ in a vertical plane; $\theta_{A}$ is for body $\mathrm{A}$ and $\theta_{B i}$ is for each stern float $\mathrm{B}$. The wind turbine platform corresponds to body A only

tero Moreno (2020a) for the WEC M4 and in Stansby et al. (2019) for the wind platform, unified here. The modification for directional waves is considered separately. The main modes are heave, surge and pitch but roll and sway motion are included for directional waves and because mechanical damping for the WEC is asymmetric about the centreline. Yaw is not included as the platform aligns with the mean wave directions. The wind platform is symmetric about the centreline and roll and sway are not considered.

\subsection{Notation}

Mathematical notation is shown in Fig. 5. Angular rotation $\theta$ is clockwise positive, $h$ is longitudinal horizontal distance from $\mathrm{O}$ to a float positive in stern direction, $v$ is vertical distance from $\mathrm{O}$ to a float positive below $\mathrm{O}, t$ is transverse horizontal distance from $\mathrm{O}$ positive on starboard side. $H, V$ and $T$ are total hydrodynamic forces in conventional $x, z, y$ directions, $M$ is pitch moment about $\mathrm{O}$ and $M_{\mathrm{R}}$ is the roll moment. The general form can be reduced for either the wave or wind platform.

Although there are multiple floats $(N)$, body A may be considered as a single body ( $N_{\mathrm{A}}$ floats) with floats B ( $N_{\mathrm{B}}$ floats) acting individually as shown in Fig. 5. There are $N_{\mathrm{m}}$ masses (floats, ballast, beams, turbine and support) with $N_{\mathrm{mA}}$ and $N_{\mathrm{mB}}$ corresponding to A and B floats.
Fig. 4 Video frames in the Cork Lir ocean basin: a 132 wave energy platform M4; note the red mooring buoy is partially submerged; $\mathbf{b}$ wind turbine platform
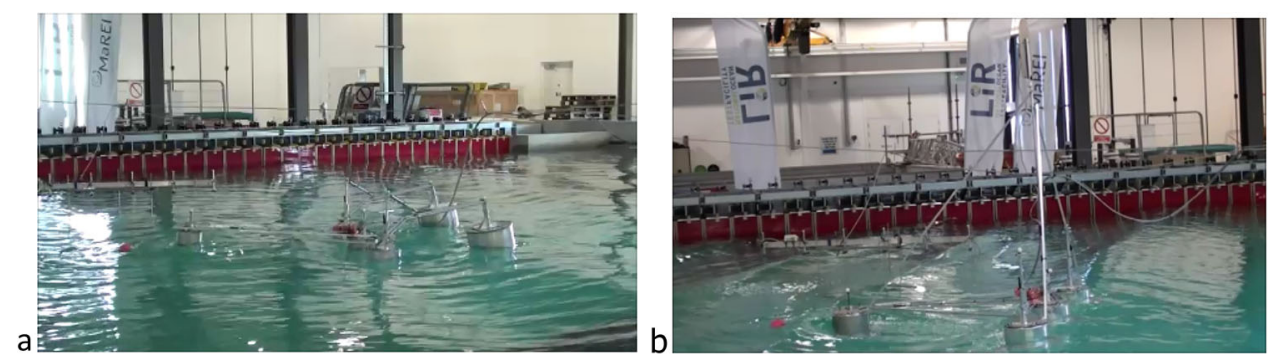


\subsection{Equations of motion}

For body A, taking moments about the y axis through $\mathrm{O}$ accounting for mooring force

$$
\begin{gathered}
-\sum_{i=1}^{N_{\mathrm{mA}}} m_{i} v_{i}^{*} \ddot{x}_{i}-\sum_{i=1}^{N_{\mathrm{mA}}} m_{i} h_{i}^{*} \ddot{z}_{i}+I_{\mathrm{A}} \ddot{\theta}_{\mathrm{A}} \\
=M_{\mathrm{mech}}+M_{\text {wind }}+\sum_{i=1}^{N_{\mathrm{A}}} M_{i}-\sum_{i=1}^{N_{\mathrm{A}}} h_{i}^{*} V_{i} \\
-\sum_{i=1}^{N_{\mathrm{A}}} v_{i}^{*} H_{i}+v_{\mathrm{M}}^{*} H_{\mathrm{M}}-h_{\mathrm{M}}^{*} V_{\mathrm{M}}
\end{gathered}
$$

where lever arms $v_{i}^{*}=\left(v_{i}+h_{i} \theta_{i}\right)$ and $h_{i}^{*}=\left(h_{i}-v_{i} \theta_{i}\right)$ introduce further first order terms. $I$ is moment of inertia about centre of mass, $M_{\text {mech }}$ is due to mechanical damping or PTO at $\mathrm{O} ; M_{\text {wind }}$ is due to the turbine thrust $H_{\text {wind }}$ defined below in Eq. (22); $H_{\mathrm{M}}$ and $V_{\mathrm{M}}$ are horizontal and vertical mooring forces acting on the bow float, defined in Stansby and Carpintero Moreno (2020a).

For the WEC including floats B with $i=1+N_{\mathrm{A}}, N$, taking moments about $\mathrm{O}$ as each float may respond individually

$-m_{i} v_{i}^{*} \ddot{x}_{i}-m_{i} h_{i}^{*} \ddot{z}_{i}+I_{i} \ddot{\theta}_{B i}=-M_{\text {mech } i}+M_{i}-h_{i}^{*} V_{i}-v_{i}^{*} H_{i}$

where $M_{\text {mech } i}=-B_{\text {mech }} \dot{\theta}_{r i}$, total $M_{\text {mech }}=\sum_{1+N_{\mathrm{A}}}^{N} M_{\text {mech } i}$ and relative angle $\theta_{r i}=\theta_{\mathrm{A}}-\theta_{\mathrm{B} i}$.

For roll about $\mathrm{O}$ for floats $\mathrm{A}$ and $\mathrm{B}$ combined,

$$
\begin{aligned}
& \sum_{i=1}^{N_{\mathrm{m}}} m_{i} v_{R i}^{*} \ddot{y}_{i}+\sum_{i=1}^{N_{\mathrm{m}}} m_{i} t_{i}^{*} \ddot{z}_{i}+I_{\mathrm{R}} \ddot{\theta}_{\mathrm{R}} \\
& =\sum_{i=1}^{N} M_{R i}+\sum_{i=1}^{N} t_{i}^{*} V_{i}+\sum_{i=1}^{N} v_{R i}^{*} T_{i}
\end{aligned}
$$

where lever arms $v_{R i}^{*}=\left(v_{i}+t_{i} \theta_{R}\right)$ and $t_{i}^{*}=\left(t_{i}-v_{i} \theta_{R}\right)$ again with first order terms.

For the WEC system, there is no net force or moment on the hinge. In general, in the longitudinal horizontal direction:

$\sum_{i=1}^{N_{\mathrm{m}}} m_{i} \ddot{x}_{i}=\sum_{i=1}^{N} H_{i}+H_{\text {wind }}-H_{\mathrm{M}}$

in the vertical direction:

$$
\sum_{i=1}^{N_{\mathrm{m}}} m_{i} \ddot{z}_{i}=\sum_{i=1}^{N} V_{i}-V_{\mathrm{M}}
$$

and in the transverse horizontal direction

$$
\sum_{i=1}^{N_{\mathrm{m}}} m_{i} \ddot{y}_{i}=\sum_{i=1}^{N} T_{i}
$$

The positions of the centres of gravity of each mass $x_{i}, z_{i}$, $y_{i}$ in relation to $\mathrm{O}\left(x_{\mathrm{O}}, z_{\mathrm{O}}, y_{\mathrm{O}}\right)$, linearised for small angles, are defined by:

For body A masses, $i=1, N_{\mathrm{mA}}$

$x_{i}=x_{\mathrm{O}}+h_{i}^{*}-v_{i}^{*} \theta_{\mathrm{A}}$

$z_{i}=z_{\mathrm{O}}-v_{i}^{*}-h_{i}^{*} \theta_{\mathrm{A}}+t_{i}^{*} \theta_{\mathrm{R}}$

$y_{i}=y_{\mathrm{O}}+t_{i}^{*}+v_{i}^{*} \theta_{\mathrm{R}}$

For B masses, $i=1+N_{\mathrm{mA}}, N$

$x_{i}=x_{\mathrm{O}}+h_{i}^{*}-v_{i}^{*} \theta_{B i}$

$z_{i}=z_{\mathrm{O}}-v_{i}^{*}-h_{i}{ }^{*} \theta_{B i}+t_{i}^{*} \theta_{\mathrm{R}}$

$y_{i}=y_{\mathrm{O}}+t_{i}^{*}+v_{i}^{*} \theta_{\mathrm{R}}$

We thus have seven equations for seven unknowns for the WEC case $\ddot{\theta}_{\mathrm{A}}, \ddot{\theta}_{\mathrm{B} i}\left(i=1+n_{\mathrm{A}}, N\right), \ddot{\theta}_{\mathrm{R}}, \ddot{x}_{\mathrm{O}}, \ddot{z}_{\mathrm{O}}, \ddot{y}_{\mathrm{O}}$, Eqs. (1), (2), (3), (4), (5), (6), respectively, and three equations for $\ddot{x}_{\mathrm{O}}$, $\ddot{z}_{\mathrm{O}}, \ddot{\theta}_{\mathrm{A}}$ for the wind turbine case with no roll or sway. The equations may be re-arranged more conveniently.

For floats A

$$
\begin{aligned}
\ddot{\theta}_{\mathrm{A}} & \left.\sum_{i=1}^{N_{\mathrm{mA}}} m_{i} v_{i}^{* 2}+\sum_{i=1}^{N_{\mathrm{mA}}} m_{i} h_{i}^{* 2}+I_{\mathrm{A}}\right) \\
= & \sum_{i=1}^{N_{\mathrm{mA}}} m_{i} v_{i}^{*} \ddot{x}_{\mathrm{O}}+\sum_{i=1}^{N_{\mathrm{mA}}} m_{i} h_{i}^{*} \ddot{z}_{\mathrm{O}}+M_{\mathrm{mech}}+M_{\text {wind }} \\
& +\sum_{i=1}^{N_{\mathrm{A}}} M_{i}-\sum_{i=1}^{N_{\mathrm{A}}} h_{i}^{*} V_{i}-\sum_{i=1}^{N_{\mathrm{mA}}} v_{i}^{*} H_{i} \\
& +\sum_{i=1}^{N_{\mathrm{mA}}} m_{i} h_{i} t_{i} \ddot{\theta}_{\mathrm{R}}+v_{\mathrm{M}}^{*} H_{\mathrm{M}}-h_{\mathrm{M}}^{*} V_{\mathrm{M}}
\end{aligned}
$$

And for floats B $i=1+N_{\mathrm{A}}, N$

$$
\begin{aligned}
\ddot{\theta}_{B i}\left(m_{i} v_{i}^{* 2}+m_{i} h_{i}^{* 2}+I_{i}\right)= & m_{i} v_{i}^{*} \ddot{x}_{\mathrm{O}}+m_{i} h_{i}^{*} \ddot{z}_{\mathrm{O}}+m_{i} h_{i} t_{i} \ddot{\theta}_{\mathrm{R}} \\
& -M_{\mathrm{mech} i}+M_{i}-h_{i}^{*} V_{i}-v_{i}^{*} H_{i}
\end{aligned}
$$


For roll of A and B combined

$$
\begin{aligned}
\ddot{\theta}_{\mathrm{R}}\left(I_{\mathrm{R}}\right. & \left.+\sum_{i=1}^{\mathrm{N}_{\mathrm{m}}} m_{i} v_{R i}^{*} v_{i}^{*}+\sum_{i=1}^{N_{\mathrm{m}}} m_{i} t_{i}^{* 2} \ddot{\theta}_{\mathrm{R}}\right) \\
= & -\sum_{i=1}^{N_{\mathrm{m}}} m_{i} v_{R i}^{*} \ddot{y}_{\mathrm{O}}-\sum_{i=1}^{N_{\mathrm{m}}} m_{i} t_{i}^{*}\left(\ddot{z}_{\mathrm{O}}-h_{i}^{*} \ddot{\theta}_{i}\right) \\
& +\sum_{i=1}^{N} M_{R i}+\sum_{i=1}^{N} t_{i}^{*} V_{i}+\sum_{i=1}^{N} v_{R i}^{*} T_{i}
\end{aligned}
$$

For the whole system,

in the horizontal longitudinal direction:

$\ddot{x}_{\mathrm{O}} \sum_{i=1}^{N_{\mathrm{m}}} m_{i}=\sum_{i=1}^{N} H_{i}-H_{\mathrm{M}}+\sum_{i=1}^{N_{\mathrm{m}}} m_{i} v_{i}^{*} \ddot{\theta}_{i}$

in the vertical direction:

$\ddot{z}_{\mathrm{O}} \sum_{i=1}^{N_{\mathrm{m}}} m_{i}=\sum_{i=1}^{N} V_{i}-V_{\mathrm{M}}+\sum_{i=1}^{N_{\mathrm{m}}} m_{i} h_{i}^{*} \ddot{\theta}_{i}-m_{i} t_{i} \ddot{\theta}_{\mathrm{R}}$

and in the transverse direction:

$\ddot{y}_{\mathrm{O}} \sum_{i=1}^{N_{\mathrm{m}}} m_{i}=\sum_{i=1}^{N} T_{i}+\sum_{i=1}^{N_{\mathrm{m}}} m_{i} t_{i}^{*} \ddot{\theta}_{\mathrm{R}}$

We thus have, for the most general case, equations for $\ddot{\theta}_{\mathrm{A}}$, $\ddot{\theta}_{\mathrm{B}}, \ddot{\theta}_{\mathrm{R}}, \ddot{x}_{\mathrm{O}}, \ddot{y}_{\mathrm{O}}, \ddot{z}_{\mathrm{O}}$ which are further complicated by $H_{i}, V_{i}$, $M_{i}, T_{i}, M_{R i}$ defined in Sect. 3.4, also being a function of these parameters and hydrodynamic (WAMIT) coefficients. To restrain sway mode, $y_{\mathrm{O}}$ may be set to zero.

\subsection{Wave spectrum}

We are concerned with irregular waves with the standard JONSWAP spectrum $S(f)$ defined by a significant wave height $H_{\mathrm{s}}$, a peak frequency $f_{\mathrm{p}}=1 / T_{\mathrm{p}}$ where $T_{\mathrm{p}}$ is the peak period, and a spectral peakedness factor $\gamma$. Although the measured spectrum was always close to the target in the experiments, the measured spectrum was input into the model. The surface elevation $\eta$ at the mid-float may be defined by linear superposition of the discretised wave amplitude components

$\eta(t)=\sum_{k=1}^{K} a_{k} \cos \left(-k 2 \pi \Delta f t+\varphi_{r, k}\right)$

where the upper limit on frequency was generally $f_{\max }=4.0$ $\mathrm{Hz}$, between 3 and 8 times $f_{\mathrm{p}}, \Delta f=f_{\max } / K, a_{k}=$
Table 1 WAMIT mode notation

\begin{tabular}{lll}
\hline WAMIT notation & & \\
\hline Body $i$ & Mode number & Symbol \\
\hline Surge & $1+6(i-1)$ & $H$ \\
Sway & $2+6(i-1)$ & $T$ \\
Heave & $3+6(i-1)$ & $V$ \\
Roll & $4+6(i-1)$ & $M_{\mathrm{R}}$ \\
Pitch & $5+6(i-1)$ & $M$ \\
\hline
\end{tabular}

$\sqrt{2 S(f) \Delta f}$, and $\varphi_{r}$ is phase from a uniform random distribution between 0 and $2 \pi$. $K$ is generally set to 200 (400 produced almost identical results).

\subsection{Hydrodynamic forces and moments}

Hydrodynamic moments and forces are defined using WAMIT notation as shown in Table 1.

Linear diffraction forces and moments for each float are defined by frequency-dependent coefficients for amplitude $F$ and phase $\varphi$, as given in Stansby and Carpintero Moreno (2020a). For each float, $i=1, N$ :

Pitch moment,

$M_{D 5+6(i-1)}=\sum_{k=1}^{K} a_{k} F_{5+6(i-1), k} \cos \left(-k 2 \pi \Delta f t+\varphi_{5+6(i-1), k}+\varphi_{r, k}\right)$

Roll moment,

$M_{D 4+6(i-1)}=\sum_{k=1}^{K} a_{k} F_{4+6(i-1), k} \cos \left(-k 2 \pi \Delta f t+\varphi_{4+6(i-1), k}+\varphi_{r, k}\right)$

Vertical force,

$V_{D 3+6(i-1)}=\sum_{k=1}^{K} a_{k} F_{3+6(i-1), k} \cos \left(-k 2 \pi \Delta f t+\varphi_{3+6(i-1), k}+\varphi_{r, k}\right)$

Longitudinal horizontal force,

$H_{D 1+6(i-1)}=\sum_{k=1}^{K} a_{k} F_{1+6(i-1), k} \cos \left(-k 2 \pi \Delta f t+\varphi_{1+6(i-1), k}+\varphi_{r, k}\right)$

Transverse horizontal force,

$T_{D 2+6(i-1)}=\sum_{k=1}^{K} a_{k} F_{2+6(i-1), k} \cos \left(-k 2 \pi \Delta f t+\varphi_{2+6(i-1), k}+\varphi_{r, k}\right)$ 
Added mass and radiation damping forces and moments are defined by frequency-dependent coefficients $A$ and $B$, respectively, using the Cummins method. With a single body and one degree of freedom $x$, we have

$m \ddot{x}(t)=f(t)-A^{\infty} \ddot{x}(t)-\int_{-\infty}^{t} L(t-\tau) \dot{x}(\tau) \mathrm{d} \tau$

where $f$ includes forces due to excitation, restoring and PTO; $A^{\infty}$ is added mass for infinite frequency and the impulse response function for radiation damping is given by

$L(t)=\frac{2}{\pi} \int_{0}^{\infty} B(\omega) \cos (\omega t) \mathrm{d} \omega$

In discrete form with time step $\Delta t$, time $t=n \Delta t$ and $\omega=2 \pi f=k \Delta \omega$

$L^{m}=\frac{2}{\pi} \sum_{k=0}^{K} B_{k} \cos (k \Delta \omega n \Delta t) \Delta \omega$

which is precomputed and in discrete form

$-\int_{-\infty}^{t} L(t-\tau) \dot{x}(\tau) \mathrm{d} \tau=-\sum_{l=n-2 \mathcal{M}}^{n} L^{n-l} \dot{x}^{l} \Delta \tau$

where $\Delta \tau=\Delta t$ and $\mathcal{M}=T_{\mathrm{p}} / \Delta t$. The lower limit $(m-2 \mathcal{M})$ was generally used to represent $-\infty$ with almost identical results given by $(m-4 \mathcal{M})$.

The RHS is generalised for each float with six modes.

For each float $i=1, N$ pitch moment is defined by:

$$
\begin{aligned}
M_{i}= & M_{D 5+6(i-1)}-\sum_{j=1}^{n} A^{\infty}{ }_{5+6(i-1), 5+6(j-1)} . \ddot{\theta}_{j} \\
& -\sum_{j=1}^{n} \int_{-\infty}^{t} L_{5+6(i-1), 5+6(j-1)}(t-\tau) \dot{\theta}_{j}(\tau) \mathrm{d} \tau \\
& -\sum_{j=1}^{n} A^{\infty}{ }_{5+6(i-1), 4+6(j-1)} \cdot \ddot{\theta}_{R j} \\
& -\sum_{j=1}^{n} \int_{-\infty}^{t} L_{5+6(i-1), 4+6(j-1)}(t-\tau) \dot{\theta}_{R j}(\tau) \mathrm{d} \tau \\
& -\sum_{j=1}^{n} A^{\infty}{ }_{5+6(i-1), 1+6(j-1)} \cdot \ddot{x}_{j} \\
& -\sum_{j=1}^{n} \int_{-\infty}^{t} L_{5+6(i-1), 1+6(j-1)}(t-\tau) \dot{x}_{j}(\tau) \mathrm{d} \tau
\end{aligned}
$$

$$
\begin{aligned}
& -\sum_{j=1}^{n} A^{\infty}{ }_{5+6(i-1), 3+6(j-1) \cdot \ddot{z}_{j}} \\
& -\sum_{j=1}^{n} \int_{-\infty}^{t} L_{5+6(i-1), 3+6(j-1)}(t-\tau) \dot{z}_{j} \mathrm{~d} \tau \\
& -\sum_{j=1}^{n} A^{\infty} 5+6(i-1), 2+6(j-1) \cdot y_{j} \\
& -\sum_{j=1}^{n} \int_{-\infty}^{t} L_{5+6(i-1), 2+6(j-1)}(t-\tau) \dot{y}_{j} \mathrm{~d} \tau+M_{\text {rest }}
\end{aligned}
$$

where the subscript rest indicates restoring moment, defined below. There is an equivalent expression for roll moment.

As an example of force, the vertical force for each float $i=1, N$ is defined by:

$$
\begin{aligned}
V_{i}= & V_{D 3+6(i-1)}-\sum_{j=1}^{n} A_{3+6(i-1), 5+6(j-1)}^{\infty} \\
& . \ddot{\theta}_{j} \sum_{j=1}^{n} \int_{-\infty}^{t} L_{3+6(i-1), 5+6(j-1)}(t-\tau) \dot{\theta}_{j}(\tau) \mathrm{d} \tau \\
& -\sum_{j=1}^{n} A^{\infty}{ }_{3+6(i-1), 4+6(j-1)} \cdot \ddot{\theta}_{R j} \\
& -\sum_{j=1}^{n} \int_{-\infty}^{t} L_{3+6(i-1), 4+6(j-1)}(t-\tau) \dot{\theta}_{R j}(\tau) \mathrm{d} \tau \\
& -\sum_{j=1}^{n} A^{\infty}{ }_{3+6(i-1), 1+6(j-1)} \cdot \ddot{x}_{j} \\
& -\sum_{j=1}^{n} \int_{-\infty}^{t} L_{3+6(i-1), 1+6(j-1)}(t-\tau) \dot{x}_{j}(\tau) \mathrm{d} \tau \\
& -\sum_{j=1}^{n} A^{\infty}{ }_{3+6(i-1), 3+6(j-1)} \cdot \ddot{z}_{j} \\
& -\sum_{j=1}^{n} \int_{-\infty}^{t} L_{3+6(i-1), 3+6(j-1)}(t-\tau) \dot{z}_{j}(\tau) \mathrm{d} \tau \\
& -\sum_{j=1}^{n} A^{\infty}{ }_{3+6(i-1), 2+6(j-1)} \cdot \ddot{y}_{j} \\
& -\sum_{j=1}^{n} \int_{-\infty}^{t} L_{3+6(i-1), 2+6(j-1)}(t-\tau) \dot{y}_{j}(\tau) \mathrm{d} \tau \\
& V_{\mathrm{drag} i} \\
&
\end{aligned}
$$

where the subscript drag indicates drag force, described below. There are equivalent expressions for longitudinal horizontal forces $H_{i}$ and transverse horizontal forces $T_{i}$. There is 
Table 2 Restoring moment factors about $\mathrm{O}$

\begin{tabular}{lcl}
\hline Floats & $\begin{array}{l}\text { Restoring moment } \\
\text { about O factor (c) } \\
(\mathrm{Nm} / \mathrm{rad})\end{array}$ & $\begin{array}{l}\text { Metacentric height } \\
(\mathrm{m})\end{array}$ \\
\hline WEC floats A pitch & 10.97 & 0.236 \\
$\begin{array}{l}\text { WEC floats A + B } \\
\text { roll }\end{array}$ & -20.9 & 0.570 \\
$\begin{array}{l}\text { WEC float B pitch } \\
\text { Wind floats pitch }\end{array}$ & -7.22 & 0.044 \\
$\begin{array}{l}\text { Wind floats roll (not } \\
\text { used) }\end{array}$ & 11.1 & 0.435 \\
\hline
\end{tabular}

an additional mean longitudinal force due to hydrodynamic drift.

The restoring heave force for a single float is given simply by: $V_{\text {rest }}=-\rho g \pi r^{2} z$ where $r$ is float radius $\left(H_{\text {rest }}=T_{\text {rest }}=\right.$ $0)$. For pitch, the restoring moment about $\mathrm{O}, M_{\text {rest }}=c \theta$, is due to the components of weight and buoyancy and the water plane restoring moment $-\rho g \pi \frac{r^{4}}{4} \theta$, although the heave restoring force dominates markedly. Values of factor $c$, and metacentric height, are shown in Table 2 for float combinations.

\subsection{Drag and wind thrust}

The heave drag force is given by $V_{\mathrm{drag} i}=-0.5 \rho \pi r_{i}^{2} C_{\mathrm{D}}$ $\left|\dot{z}_{i}\right| \dot{z}_{i}$. Note float velocity relative to flow velocity is not considered and drag coefficient $C_{\mathrm{D}}$ is effectively a viscous tuning parameter.

For damping plates, Tao and Thiagarajan (2003) showed $C_{\mathrm{D}}>4$ for heave and $C_{\mathrm{D}} \approx 6$ was a representative value, although dependent slightly on amplitude of motion. For heave, $C_{\mathrm{D}}=6$ is assumed and $C_{\mathrm{D}}=0$ for surge and sway since the horizontal cross section of each float is circular and zero proved effective for WEC simulations with rounded base floats; CFD also showed drag coefficient was very small $(\mathrm{Gu}$ et al. 2018). Tao and Thiagarajan (2003) also produced a simple formula for added mass in heave and that obtained from WAMIT was within $1 \%$ providing a useful cross-check.

The wind thrust is given by

$$
H_{\text {wind }}=0.5 \rho_{\text {air }} A_{\text {turb }} C_{\mathrm{T}}\left(U_{\text {hub }}-\dot{x}_{\text {hub }}\right)^{2}
$$

where $U_{\text {hub }}$ is wind speed at the hub, $\dot{x}_{\text {hub }}$ is hub velocity, $\rho_{\text {air }}$ is air density and $A_{\text {turb }}$ is the swept area for the rotor of radius $r_{\text {turb }}, \pi r_{\text {turb }}^{2}$. The thrust coefficient $C_{\mathrm{T}}$ is dependent on the wind speed and is determined from blade element momentum theory using the NREL $5 \mathrm{MW}$ turbine characteristics (Jonkman et al. 2009). The force is assumed to be quasisteady and defined by the relative velocity $\left(U_{\text {hub }}-\dot{x}_{\text {hub }}\right)$; note the rotation speed is also dependent on wind speed. The quasi-steady behaviour has been shown to be a close approx- imation by Apsley and Stansby (2020). The $C_{\mathrm{T}}, U_{\text {hub }}$ curve is shown in Fig. 6 at full scale with a cut in of $3 \mathrm{~m} / \mathrm{s}$ and a cut out of $25 \mathrm{~m} / \mathrm{s}$. We are concerned with range $5-20 \mathrm{~m} / \mathrm{s}$ shown.

For the purposes of this demonstration, the wind velocity at the hub is assumed uniform across the swept area. The moment about $\mathrm{O}$ in Eqs. (1), (8) is $M_{\text {wind }}=-v_{\text {hub }} H_{\text {wind }}$.

\subsection{Power calculations}

The total mechanical power for the WEC case is given by

$P_{\text {mech }}=\sum_{i=1+N_{\mathrm{A}}}^{N}\left[\int_{t_{1}}^{t_{2}} B_{\text {mech } i} \dot{\theta}_{r i}^{2} \mathrm{~d} t\right] /\left(t_{2}-t_{1}\right)$

The averaged radiated wave power results from all floats driven by pitch moment $M^{\text {rad }}$, roll moment $M_{\mathrm{R}}{ }^{\mathrm{rad}}$, heave force $V^{\mathrm{rad}}$ and surge force $H^{\mathrm{rad}}$, sway force $T^{\mathrm{rad}}$, and is given by

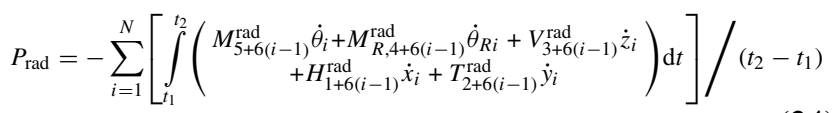

The power absorbed by drag only occurs in the heave direction and is given by

$P_{\text {drag }}=-\sum_{i=1}^{N}\left[\int_{t_{1}}^{t_{2}} V_{\text {drag } i} \dot{z}_{i} \mathrm{~d} t\right] /\left(t_{2}-t_{1}\right)$

And the power absorbed by the wind turbine is given by

$P_{\text {wind }}=-\int_{t_{1}}^{t_{2}} \dot{x}_{\text {hub }} H_{\text {wind }} \mathrm{d} t /\left(t_{2}-t_{1}\right)$

In addition, there are second-order hydrodynamic forces associated with a fixed body due to sum and difference frequencies which are small but the zero difference frequencies generate a mean drift force. There are additional horizontal mean forces due to the time-average mechanical power absorption $P_{\text {mech }}$, the power required by float motion to radiate waves $P_{\text {rad }}$ and the power absorbed by drag $P_{\text {drag }}$. This power absorbed from oncoming waves is balanced by the horizontal energy flux with a representative wave speed giving a horizontal force, also of second order. This argument was described for two-dimensional problems in (Mei 1999) (Sect. 7.10). The power absorbed is first determined from a linear computation giving motions without moorings, which have negligible effect (Stansby and Carpintero Moreno 2020a). The total mean force may thus be calculated. This underestimated the measured mean mooring force (by up to 
Fig. 6 Variation of thrust coefficient $C_{T}$ with full-scale wind speed at hub $U_{\mathrm{hub}}$, from Jonkman et al. (2009)

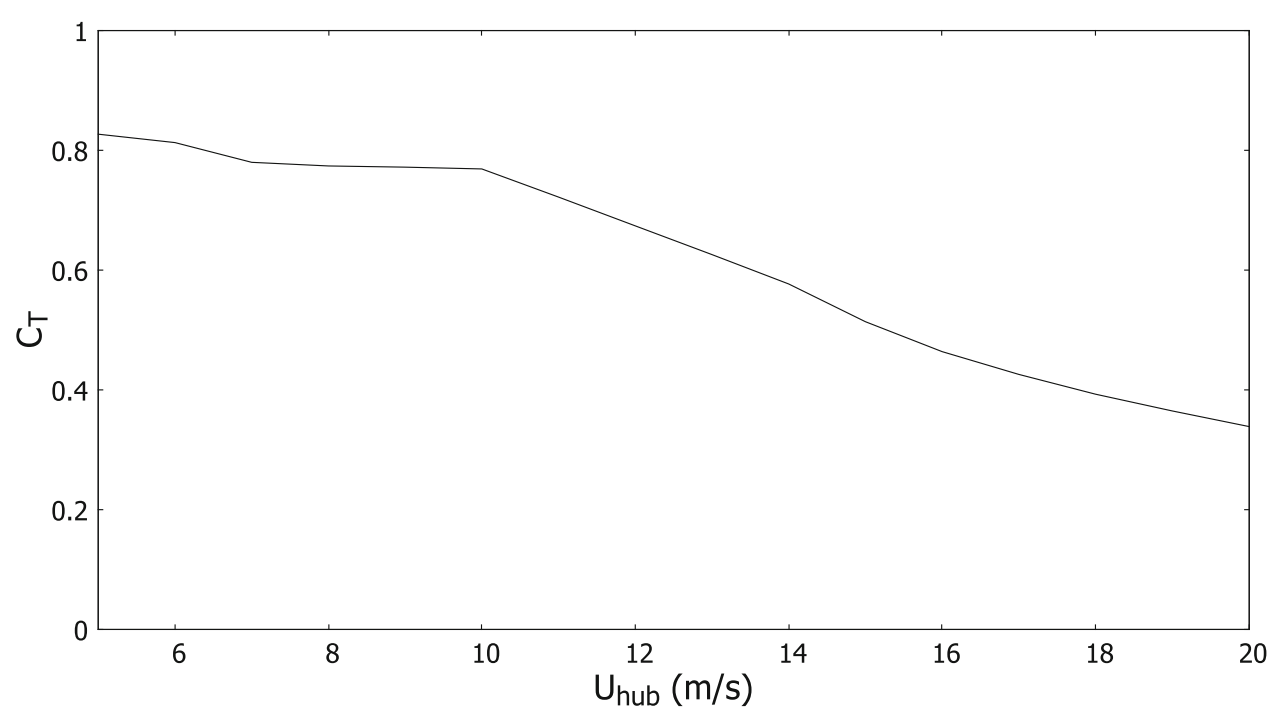

$50 \%$ ) and the experimental magnitude was generally used as input to the model (Stansby et al. 2019; Stansby and Carpintero Moreno 2020a). The influence of mean force remains to be resolved for mooring design (Stansby and Carpintero Moreno 2020b).

\subsection{Time stepping}

The parameters $\theta_{\mathrm{A}}, \theta_{\mathrm{B}}, \theta_{\mathrm{R}}, x_{\mathrm{O}}, z_{\mathrm{O}}, y_{\mathrm{O}}$ and their time derivatives were advanced in time with step $\Delta t$ with the example in Eq. 27 below for $\theta_{\mathrm{A}}$

$\theta_{\mathrm{A}}^{n+1}=\theta_{\mathrm{A}}^{n}+\dot{\theta}_{\mathrm{A}}^{n} \Delta t+\ddot{\theta}_{\mathrm{A}}^{n} \Delta t^{2} / 2$

$\dot{\theta}_{\mathrm{A}}^{n+1}=\dot{\theta}_{\mathrm{A}}^{n}+\ddot{\theta}_{\mathrm{A}}^{n} \Delta t$

Note $\theta_{B}$ does not apply to the wind platform case and $\theta_{\mathrm{R}}$ and $y_{\mathrm{O}}$ are not considered. For the wave platform, there are two $\theta_{\mathrm{B}}$ parameters for the 132 case and four for the 134 case.

The WAMIT coefficients are for all cross-coupled terms between floats as well as for the directly coupled (diagonal) terms which have greatest magnitude. Forming a direct formulation for each of $\ddot{\theta}_{\mathrm{A}}, \ddot{\theta}_{\mathrm{B}}, \ddot{\theta}_{\mathrm{R}}, \ddot{x}_{\mathrm{O}}, \ddot{z}_{\mathrm{O}}, \ddot{y}_{\mathrm{O}}$ (for the most general wave platform case) with all cross-coupled terms is difficult to generalise. However, the dominant diagonal terms in added mass for each of $\ddot{\theta}_{\mathrm{A}}, \ddot{\theta}_{\mathrm{B}}, \ddot{\theta}_{\mathrm{R}}, \ddot{x}_{\mathrm{O}}, \ddot{z}_{\mathrm{O}}, \ddot{y}_{\mathrm{O}}$ may be removed from each of $H_{i}, V_{i}, M_{i}, M_{R i}$ and added to the LHS of Eqs. (8), (9), (10), (11), (12), (13). This proved desirable for numerical stability. Iteration is still required with updated values of $\ddot{\theta}_{\mathrm{A}}, \ddot{\theta}_{\mathrm{B}}, \ddot{\theta}_{\mathrm{R}}, \ddot{x}_{\mathrm{O}}, \ddot{z}_{\mathrm{O}}, \ddot{y}_{\mathrm{O}}$ for terms on the RHS but this showed fast convergence, with less than 10 iterations (default value). The radiation damping and diffraction force terms were not modified in the iteration. A time step size of $T_{\mathrm{p}} / 200$ was sufficiently small to give converged results (to plotting accuracy). The equation set with numerical solu- tion is thus complete and proved stable and convergent. The computer time for a run is small, order one minute on a laptop.

\section{Modification for directional spread waves}

There are various options for generating directional waves, e.g. Latheef et al. (2017). The directional wave spectrum is usually defined by $S(f, \theta)=S(f) . G(\theta)$ where the spreading function

$G(\theta)=\alpha\left(\cos \frac{\theta}{2}\right)^{2 s}$

with the mean wave direction given by $\theta=0$, for $-\pi<$ $\theta<\pi$, and $s$ is the spreading parameter. $\alpha$ is defined by the requirement $\int_{-\pi}^{\pi} G(\theta) \mathrm{d} \theta=1$. One approach for generating directional waves is to split each frequency component into directions defined by $G(\theta)$ known as the double summation method. However, this means that a specific frequency has several directional components and partial standing waves result; the wave field is non-ergodic (Jefferys 1987). To avoid this, each frequency component may be sub-divided into a number of smaller components with different frequencies which together satisfy the spreading across the original frequency band, known as the single summation method. An equivalent more efficient approach, often employed experimentally, is known as the random directional method (Latheef et al. 2017). The direction of propagation of any one frequency component is chosen randomly, subject to a weighting function based upon the desired directional spread. This approach also avoids components of the same frequency co-existing and results in ergodic wave fields. The appropriate weighting for choosing the direction of the components is based upon a normal distribution with a standard 
deviation of $\sigma_{\theta}$ in accordance with the directional distribution,

$G(\theta)=\frac{\alpha}{\sigma_{\theta} \sqrt{2 \pi}} \exp \left[-\frac{\theta^{2}}{2 \sigma_{\theta}^{2}}\right]$

where $\sigma_{\theta}^{2}=\frac{2}{1+s}$ as a close approximation to the Eq. (28) above. This is applied to each frequency component in the spectrum. The random angle is determined by the BoxMuller method where two random number numbers $\left(u_{1}\right.$, $\left.u_{2}\right)$ are first generated from a uniform distribution between 0 and 1 and then converted to a random number $u_{3}=$ $\sqrt{-2 \ln \left(u_{1}\right)} \cos \left(2 \pi u_{2}\right)$ with unit standard deviation and mean zero, giving a random angle $u_{3} \sigma_{\theta}$. This is the approach adopted here to represent the effect of directional spread waves defined by the measured spectrum and a spread factor $s$.

The excitation forces and moments are affected by the heading angle and hydrodynamic (WAMIT) coefficients are determined at $2^{\circ}$ intervals. The excitation forces and moments are as defined by Eq. (15) except that each frequency component $k$ has a random heading from the normal distribution defined above, defining the excitation coefficients.

\section{Far field wave power array model}

Power from the incident wave field is absorbed by damping imparted to wave energy converters or floating wind platforms. With platform dimension small in relation to spacing, each platform can be regarded as a point sink for power; the resultant wave power incident on a platform is the far field wave power less that due to absorption by all other platforms. Here, we assume that the onset far field is uniform and depth is constant. This is an idealisation enabling fast computation to give the wave field within the farm and down-wave of the farm. A complete analysis at a regional scale would involve spatial and temporal variation of wave propagation with a spectral model, such as SWAN or TOMAWAC, e.g. Ruehl et al. (2014), McNatt et al. (2020).

With directional spreading, the uniform onset wave power/metre is $P_{\text {onset }}$. The capture width for a given $T_{\mathrm{p}}, \gamma$ and $s$ defines the power $\Delta P$ absorbed, hence removed from the wave field. This is represented as a point sink of power $\Delta P$ which is spread at a distance $r$ such that

$\Delta P=\int P_{\theta} r \mathrm{~d} \theta=\int \Delta P G(\theta) \mathrm{d} \theta$

giving wave power/metre $P_{\theta}=\Delta P G(\theta) / r$. The wave power/metre in the $x$ direction is thus $P_{\text {onset }}-P_{\theta} \cos (\theta)$ and in the $y$ direction $-P_{\theta} \sin (\theta)$ for a single point. This gives the resultant wave power/metre and, for a device, power absorption from the capture width. If there are $N$ devices, the wave power in the $x$ and $y$ directions becomes $P_{\text {onset }}-\sum_{i} P_{\theta i} \cos$ $\left(\theta_{i}\right)$ and $-\sum_{i} P_{\theta i} \sin \left(\theta_{i}\right)$, respectively, $i=1, N$. This strictly requires an iterative procedure as each device affects every other device. However, the upwave effect is negligible and if the devices are ordered with increasing distance down-wave, one sweep is sufficient.

Note that this does not account for the frequency distribution of power absorption which could be included if known from a model while adding to the complexity. There are thus many variables and fast methods are desirable. The highly accurate idealisation is also a useful check for regional scale models.

\section{Results}

\subsection{Multi-float wave energy platform in uni-directional waves}

The 132 M4 was tested experimentally (Carpintero Moreno and Stansby 2019). The damping was almost linear but not equal on the left and right hand sides (although the same part number of pneumatic damper was used). The model prediction of rms relative angle $\theta_{\text {rel }}$ is shown in Fig. 7 to agree approximately with experiment for $H_{s} \approx 0.04 \mathrm{~m}$ and $0.06 \mathrm{~m}$ with $\gamma=3.3$, although there is some shift in peak values. The specific values of $H_{\mathrm{s}}$ and $B_{\text {mech }}$ are given in Table 5. The capture width for average mechanical power absorbed normalised by the device width (of $1.75 \mathrm{~m}$ ) is shown in Fig. 8 and the model now generally underestimates, by up to $35 \%$ near the maximum while agreement is close for longer waves $\left(T_{\mathrm{p}}>1.4 \mathrm{~s}\right)$; differences are discussed further in Sect. 7. The total capture width due to mechanical and radiated power absorbed is estimated from the model and shown to be at least twice the mechanical power. The capture width without PTO is also shown to be greater than the total with PTO indicating that this is most effective for wave energy absorption.

The capture width due to radiation is shown in Fig. 9 for $H_{\mathrm{s}}$ $\sim 4 \mathrm{~cm}$ with the split between surge, heave and pitch (summed over all floats) and that due to radiation and PTO. This shows that radiation absorption is greater than that from the PTO for $T_{\mathrm{p}}<1.4 \mathrm{~s}$ and equal for $T_{\mathrm{p}} \geq 1.4 \mathrm{~s}$. Heave radiation is greater than surge, while pitch is small. The total due to all effects is also shown.

The 132 configuration has been modified to 134 , with the 4 stern floats driving PTOs identical to those in the 132 case, shown in Fig. 10. The capture width normalised by device width from the model remains similar but with a device width of $2.45 \mathrm{~m}$ rather than $1.75 \mathrm{~m}$, as shown in Fig. 11, which includes the case without PTO. The 134 configuration with 
Fig. 7 Variation of rms $\theta_{\text {rel }}$ for right and left sides with $T_{\mathrm{p}}$ for $H_{\mathrm{s}} \sim 4$ and $6 \mathrm{~cm}$ with $\gamma=3.3$ : comparison of model with experiment for $132 \mathrm{M} 4$

Fig. 8 Variation of capture width/device width with $T_{\mathrm{p}}$ for $H_{\mathrm{s}} \sim 4$ and $6 \mathrm{~cm}$ with $\gamma=3.3$ for mechanical PTO power, total for mechanical PTO and radiation, total without $\mathrm{PTO}$ for $132 \mathrm{M} 4$ with device width of $1.75 \mathrm{~m}$

Fig. 9 Variation of capture width/device width estimated from the model with $T_{\mathrm{p}}$ for $H_{\mathrm{s}}$ $\sim 4 \mathrm{~cm}$ with $\gamma=3.3$ : capture width is total due to radiation power with components due to surge, heave and pitch, due to mechanical power, and the total: for $132 \mathrm{M} 4$ with device width of $1.75 \mathrm{~m}$
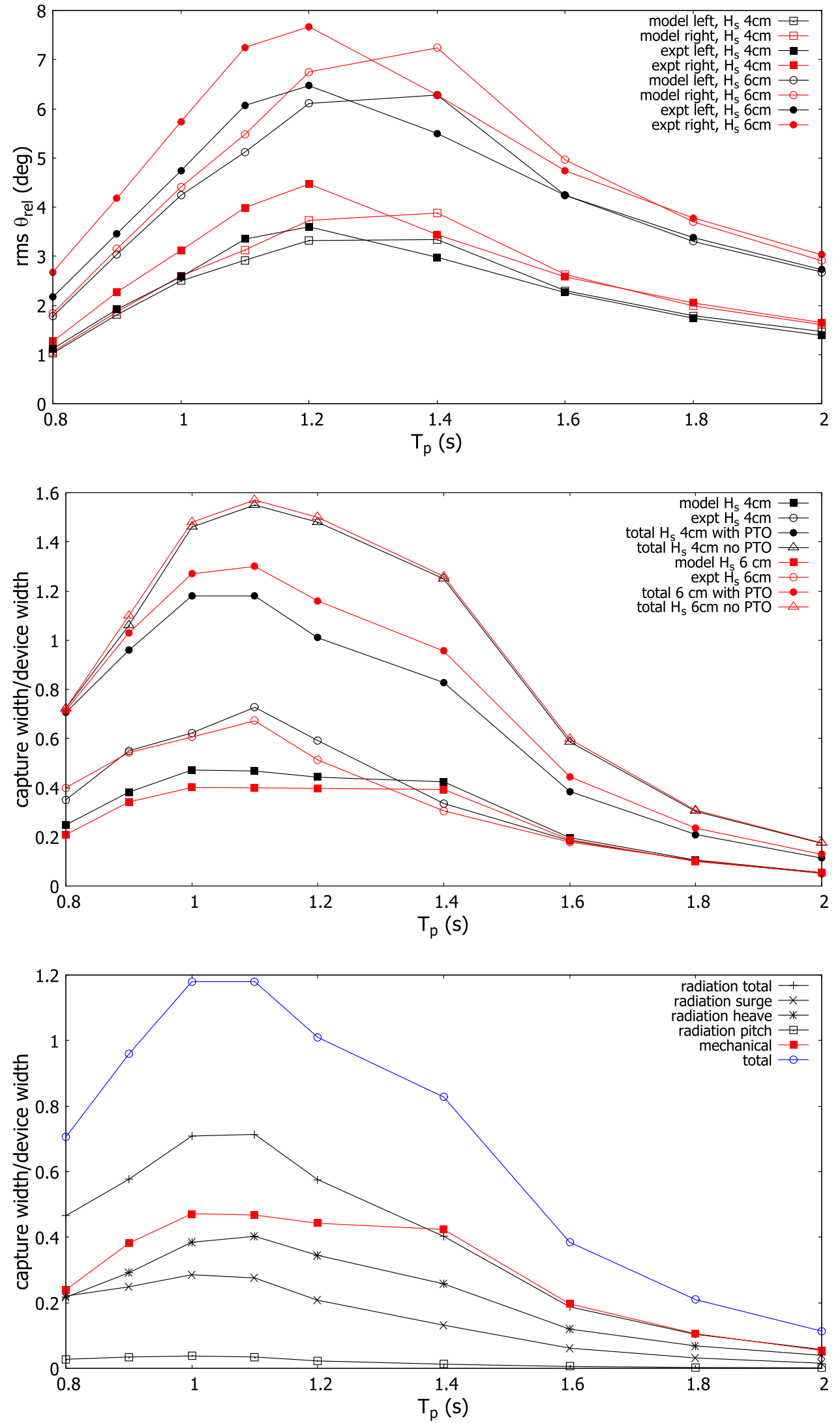


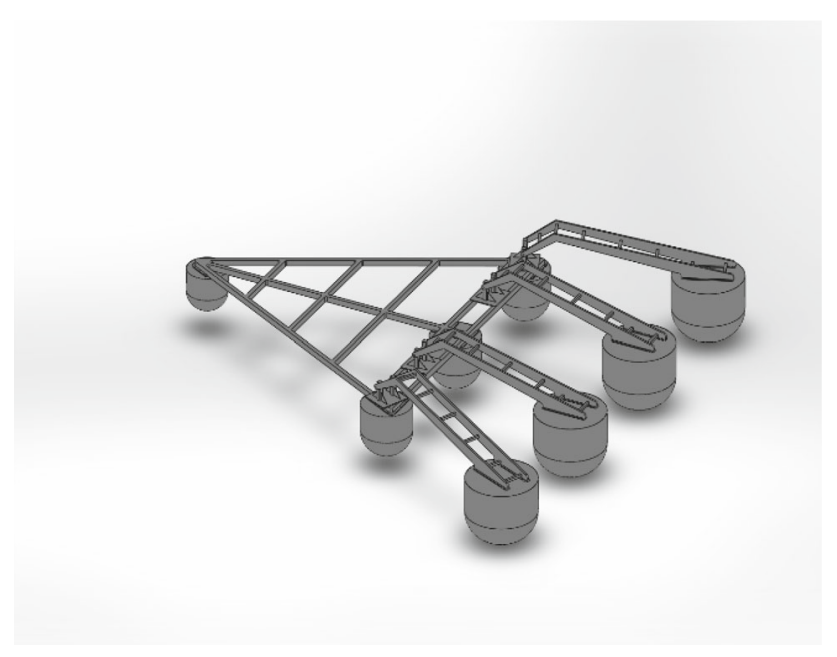

Fig. 10134 M4 configuration control and different headings has been analysed in Liao et al. (2021).

\subsection{Multi-float wave energy platform in directional spread waves}

Some data with directional spread waves are available for the $132 \mathrm{M} 4$ case with $H_{\mathrm{s}} \sim 4 \mathrm{~cm}$ and $\gamma=1$. The specific values of $H_{\mathrm{S}}$ and $B_{\text {mech }}$ are given in Table 6 . With uni-directional waves $(s=\infty)$, the model rms relative angle $\theta_{\text {rel }}$ is shown in Fig. 12, again with different left and right linear damping, to be close to experiment for the left side but with some difference on the right. The model angle is also shown without PTO. With $s=20$ in Fig. 13, the model angle is in similar agreement with experiment and also with $s=5$ in Fig. 14. The model rms roll angle is also shown to be small but significant due to multi-directional waves.
Fig. 11 Variation of capture width/device width estimated from the model with $T_{\mathrm{p}}$ for $H_{\mathrm{s}}$ $\sim 4 \mathrm{~cm}$ with $\gamma=3.3$ for $132 \mathrm{M} 4$ (width $1.75 \mathrm{~m}$ ) and $134 \mathrm{M} 4$ (width $2.45 \mathrm{~m}$ ), showing mechanical PTO power, total power due to PTO and radiation, radiated (total) power without PTO

Fig. 12 Variation of rms $\theta_{\text {rel }}$ for right and left sides with $T_{\mathrm{p}}$ for $H_{\mathrm{s}} \sim 4 \mathrm{~cm}$ with $\gamma=1$ and $s=\infty$ : comparison of model with experiment for $132 \mathrm{M} 4$, model estimate without PTO
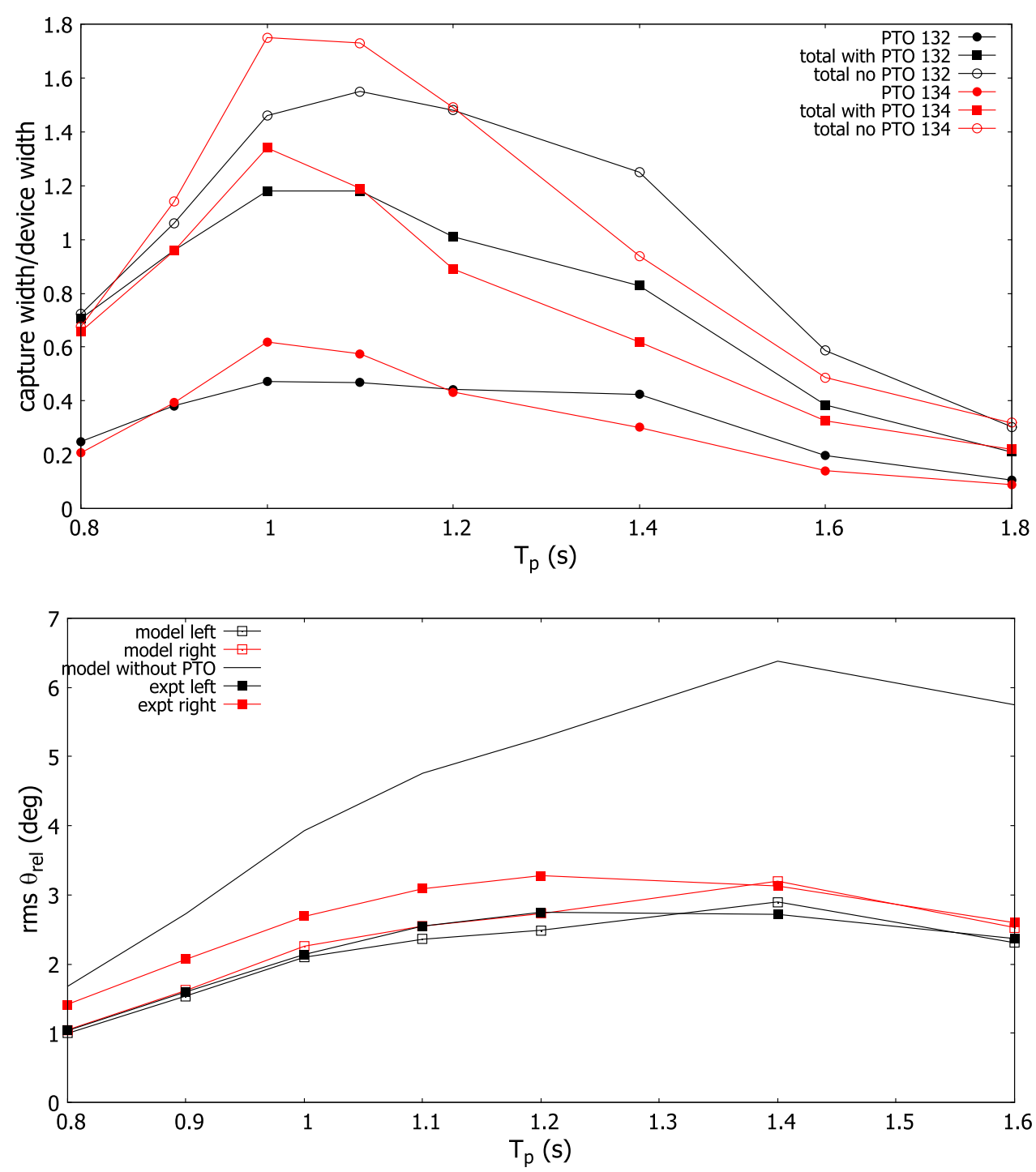
Fig. 13 Variation of rms $\theta_{\text {rel }}$ for right and left sides with $T_{\mathrm{p}}$ for $H_{\mathrm{s}} \sim 4 \mathrm{~cm}$ with $\gamma=1$ and $s=20$ : comparison of model with experiment for $132 \mathrm{M} 4$, model estimate without PTO and roll estimate with PTO

Fig. 14 Variation of rms $\theta_{\text {rel }}$ for right and left sides with $T_{\mathrm{p}}$ for $H_{\mathrm{s}} \sim 4 \mathrm{~cm}$ with $\gamma=1$ and $s=5$ : comparison of model with experiment for $132 \mathrm{M} 4$, model estimate without PTO and roll estimate with PTO

Fig. 15 Variation of capture width/device width with $T_{\mathrm{p}}$ for $H_{\mathrm{s}} \sim 4 \mathrm{~cm}$ with $\gamma=1$ and $=\infty$, 20, 5: mechanical PTO power is compared with experiment and total capture due to mechanical and radiated power is estimated from model: for $132 \mathrm{M} 4$ with device width of $1.75 \mathrm{~m}$
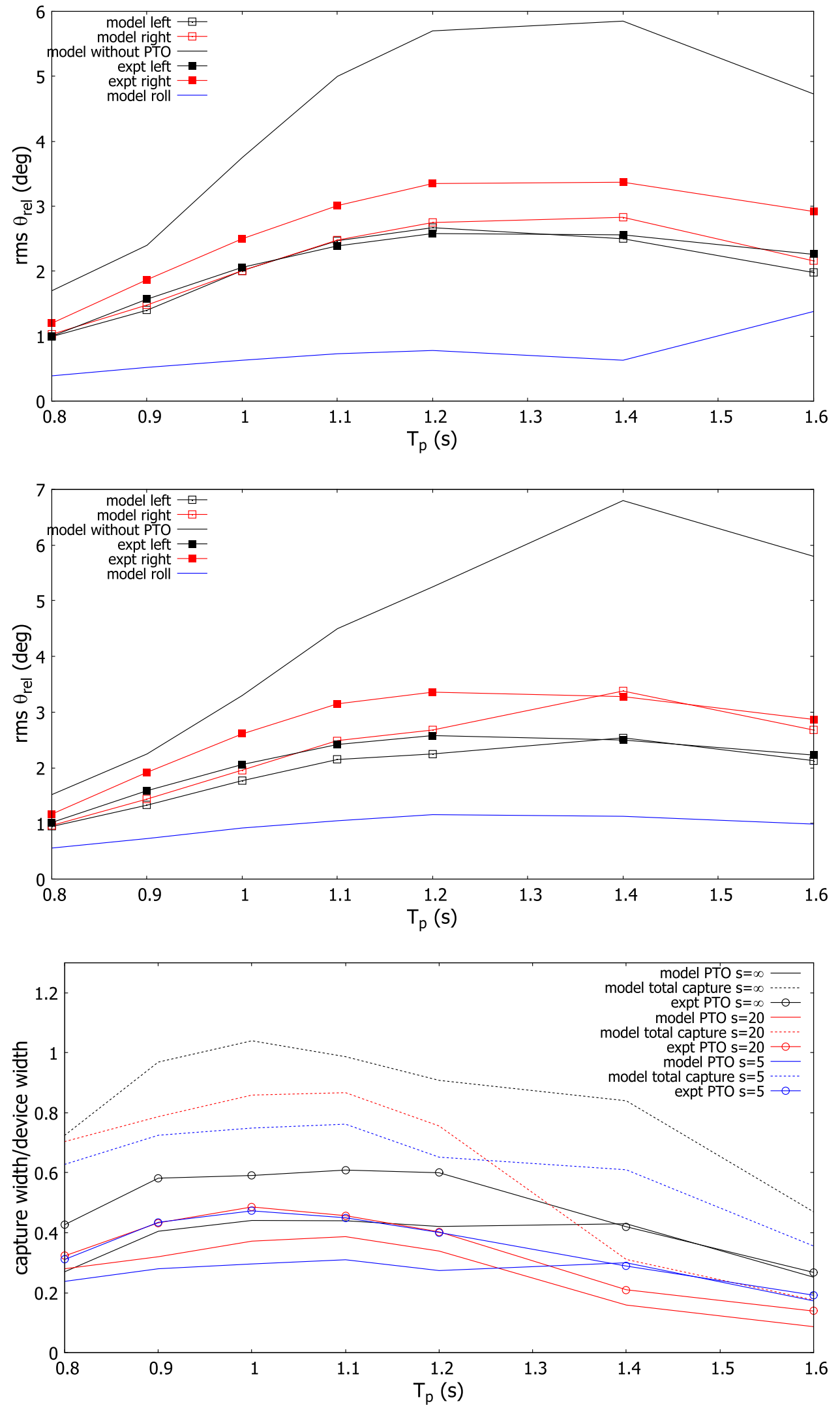
Fig. 16 Variation of capture width/device width estimated from the model with $T_{\mathrm{p}}$ for $H_{\mathrm{s}}$ $\sim 4 \mathrm{~cm}$ with $\gamma=1$ and $s=\infty$, 20, 5: capture width is for mechanical power, total due to radiated and mechanical power and due to radiated power without PTO: for $132 \mathrm{M} 4$ with device width of $1.75 \mathrm{~m}$
Fig. 17 Variation of hub and base rms acceleration with $T_{\mathrm{p}}$ for $H_{\mathrm{s}} \sim 6 \mathrm{~cm}$ with $\gamma=3.3$ showing longitudinal values for model and experiment, and rms sway values from experiment

Fig. 18 Variation of capture width/device width estimated from the model with $T_{\mathrm{p}}$ for $H_{\mathrm{S}}$ $\sim 6 \mathrm{~cm}$ with $\gamma=3.3$ showing radiated power absorbed and its components from heave, surge and pitch, drag power absorbed and total power absorbed, with device width of $1.65 \mathrm{~m}$
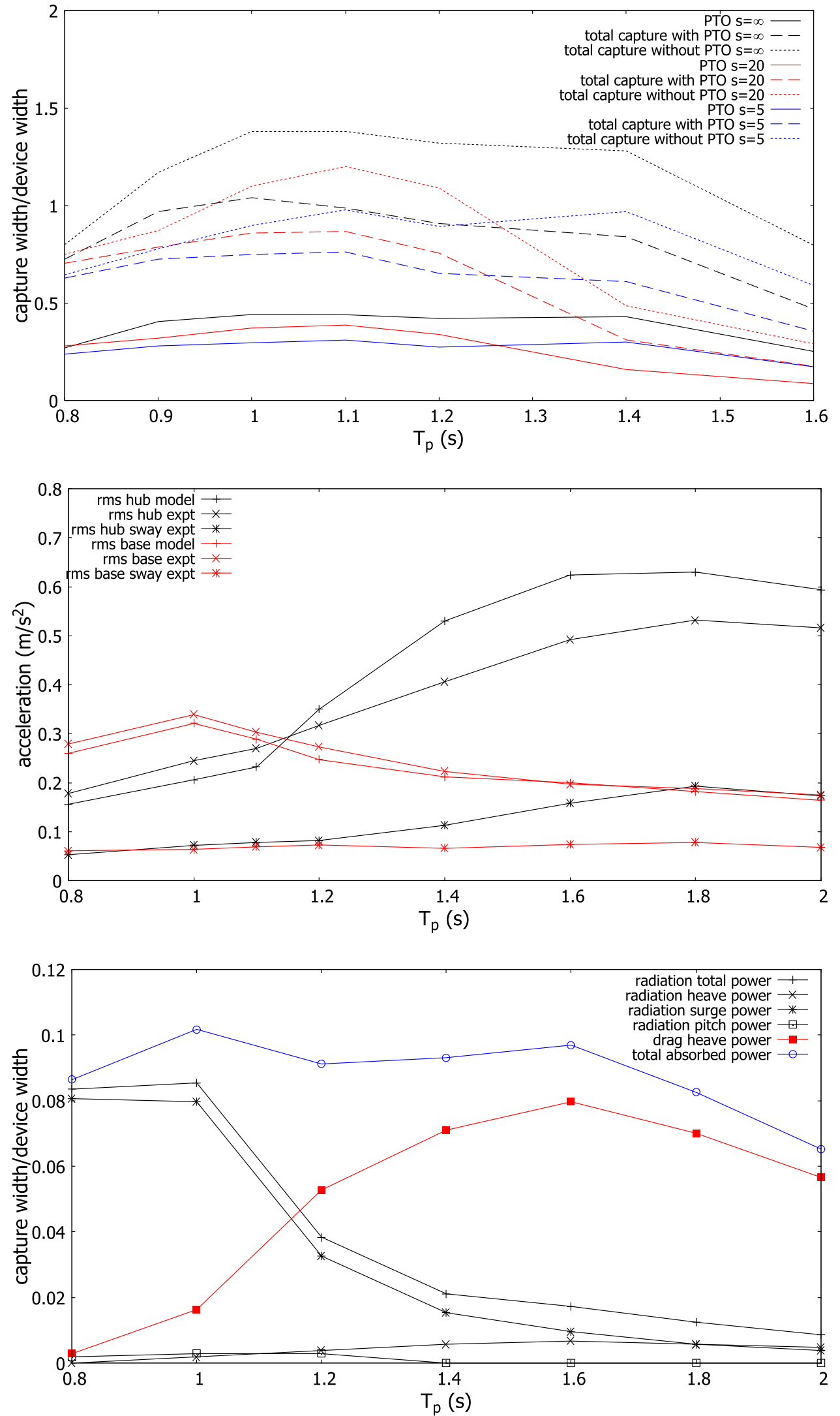
Fig. 19 Variation of capture width/device width estimated from the model with $T_{\mathrm{p}}$ for $H_{\mathrm{s}}$ $\sim 6 \mathrm{~cm}$ with $\gamma=3.3$ and wind action with velocities $U=0$, $8,12,16 \mathrm{~m} / \mathrm{s}$ (full scale), showing radiated wave + drag power absorbed and wind power absorbed, with device width of $1.65 \mathrm{~m}$

Fig. 20 Wave power transmission, normalised by onset wave power, down-wave of one and two rows of one hundred 134 M4 WECs with $s=5$ and 20; for capture widths normalised by device width $(\mathrm{nCW})$ of 1 and 1.5 ; at model scale, the spacing is 20 and $12 \mathrm{~m}$ and device width $2.45 \mathrm{~m}$

Fig. 21 Wave power transmission normalised by onset wave power down-wave of a $10 \times 10$ array of wind turbine platforms with $s=5$ and 20; for a capture width normalised by device width (nCW) of 0.1 , at model scale, the spacing is $20 \mathrm{~m}$ and device width $1.65 \mathrm{~m}$ : wave power transmission is output along a line one spacing (near) and 10 spacings (far) down-wave of the array
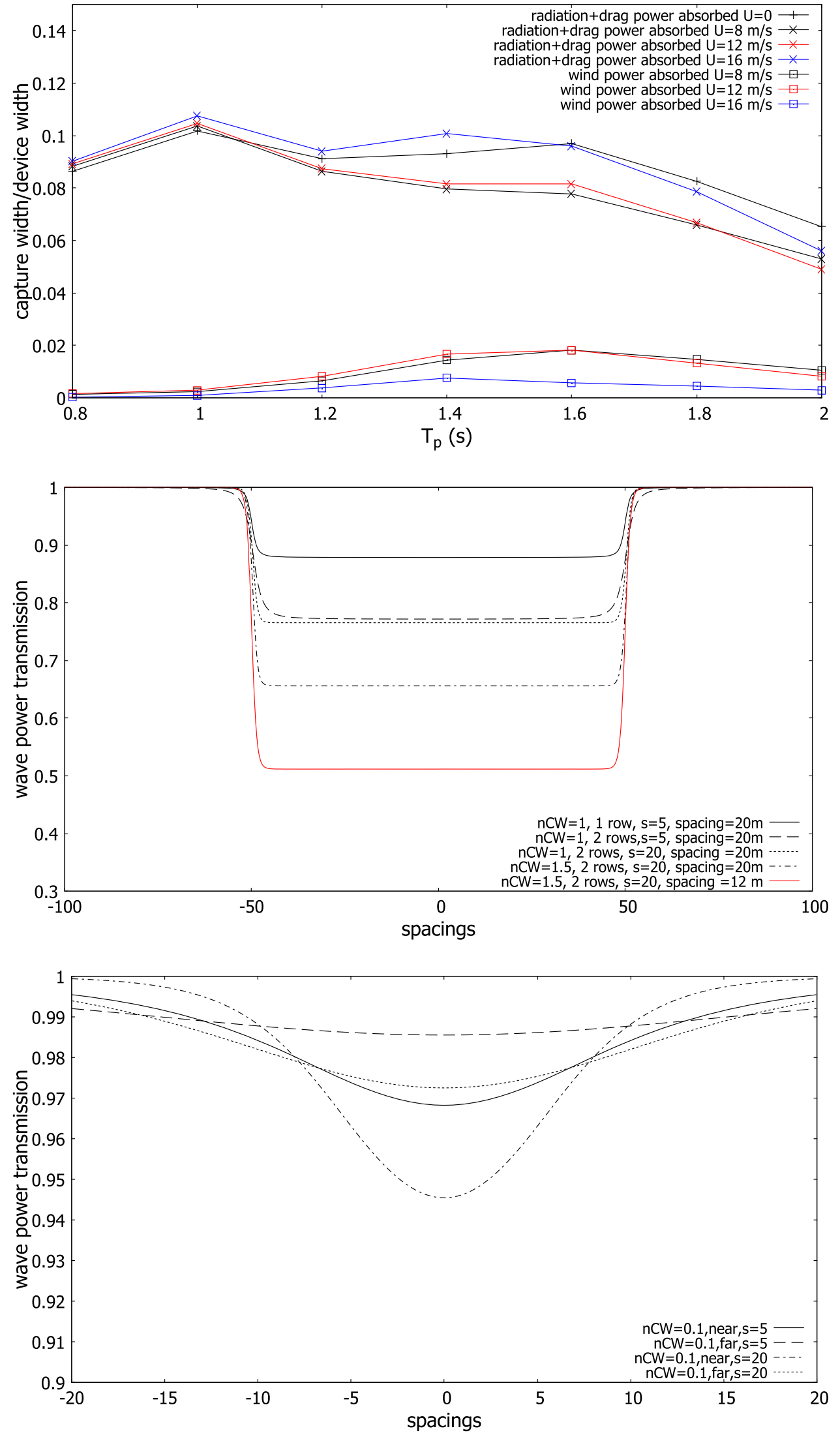
The total capture width due to radiation and PTO, estimated from the model, is shown in Fig. 15, with the experimental mechanical PTO from model and experiment. The model can again underestimate, by up to about $30 \%$ near maximum values.

The model capture width is shown in Fig. 16 to be greater without PTO than the total with PTO and radiation combined. This shows that the total capture width can be around $4 \times$ greater than that due to PTO.

\subsection{Floating wind platform in unidirectional waves}

The floating wind platform will also absorb wave power due to radiation and drag effects. For this case, hub and base accelerations have been measured and compared with experiment for $H_{s} \sim 6 \mathrm{~cm}$ with $\gamma=3.3 \mathrm{in} \mathrm{Fig.} \mathrm{17,} \mathrm{without} \mathrm{any}$ wind effect. The $H_{\mathrm{s}}$ values are as given in Table 5. Agreement between model and experiment is quite close at the base, while the model can overestimate at the hub, by up to $30 \%$. Some sway was measured in the experiment due to oscillatory vaning effect not present in the model due to symmetry.

The capture width from the model normalised by device width (now $1.65 \mathrm{~m}$ ) is shown in Fig. 18. Power absorbed by radiation is the greater component for lower $T_{\mathrm{p}}$ and mainly due to surge, while becoming similar to heave for larger $T_{\mathrm{p}}$. The contribution from pitch is negligible. However, capture width from drag dominates for the larger $T_{\mathrm{p}}$. The net effect is that total capture width is quite uniform across the range of $T_{\mathrm{p}}$, although much smaller than total capture width for the M4 WECs and smaller than the PTO capture widths (about a quarter). Experimental results with directional waves were not available for this case.

These results, presented in Fig. 18, were without wind power absorbed. The effect of representative wind speeds of 8,12 and $16 \mathrm{~m} / \mathrm{s}$ at full scale, or $1.13,1.70$ and $2.26 \mathrm{~m} / \mathrm{s}$ at a model scale of 1:50, are shown in Fig. 19 again with $H_{\mathrm{s}}$ $\sim 6 \mathrm{~cm}$. It is interesting that power absorbed due to wave radiation is always much greater than that due to wind damping (both represented as capture width), and the wave damping is largely due to drag for the larger $T_{\mathrm{p}}$. Wind damping is largest around the rated wind speed, $8-12 \mathrm{~m} / \mathrm{s}$ at full scale, when wave damping is somewhat reduced.

\subsection{Wave power transmission through arrays}

We first consider rows of WECs. Spacing should be 5 wavelengths or more for radiation from a multi-float platform to be negligible. With a typical peak period of $1.1 \mathrm{~s}$ ( $7.8 \mathrm{~s}$ full scale), the corresponding wave length is $1.9 \mathrm{~m}$, so the spacing should be at least $9.7 \mathrm{~m}$; we consider 12 and $20 \mathrm{~m}$. The total capture width/platform width is order unity and we test representative values of 1 and 1.5, noting the model can underestimate and control will increase this further. In general, capture width is defined by $T_{\mathrm{p}}, \gamma$ and $s$ with linear modelling and there will be additional non-linear effects. The input to the array model is capture width and $s$. Results for a single row of one hundred 134 devices (width $2.45 \mathrm{~m}$ ) and with two staggered rows, one spacing apart, are shown in Fig. 20 for $s=5$ and 20. The influence of $s$ is negligible. One row with a spacing of $20 \mathrm{~m}$ and a capture width of one platform width (normalised capture width $\mathrm{nCW}=1$ ) give a wave power reduction of $12 \%$ and two rows $23 \%$. With a capture width of 1.5 platform width $(\mathrm{nCW}=1.5)$, the reduction with $20 \mathrm{~m}$ spacing is $35 \%$, and with $12 \mathrm{~m}$ spacing $48 \%$.

For the wind platform, a turbine diameter of $126 \mathrm{~m}$ scales to $2.52 \mathrm{~m}$ at 1:50 model scale and turbines are normally assumed to be more than 8 diameters apart to make wake power losses acceptably small. This gives a spacing of $20.2 \mathrm{~m}$ and a value of $20 \mathrm{~m}$ is assumed. A 100 turbine farm is assumed; with a turbine capacity of $5 \mathrm{MW}$, the total capacity would be $500 \mathrm{MW}$. The platforms are placed in a $10 \times 10$ array and wave power is output one spacing down-wave of the last row (termed near), and 10 spacings down-wave (termed far). A capture width of 0.1 platform width is assumed which is probably an overestimate as directional spread will reduce this further. Results are shown in Fig. 21 for $s=5$ and 20 which clearly now have an effect. Note a row of 10 extends from -4.5 to +4.5 spacings. The wave propagation far downwave is reduced by less than about $3 \%$.

\section{Discussion}

Linear hydrodynamic modelling is used to determine mechanical and radiation power to give total power absorbed. This model provides an approximation of experimental results, with similar trends, with mechanical power capture underestimated by up to $35 \%$ near maximum capture width, while accurate for longer waves. The reason for underestimation is unknown and, in contrast, linear models for point absorbers tend to over- not underestimate power, e.g. Giorgi and Ringwood (2018). In this case, with multiple floats, nonlinear free surface interaction between floats due to radiation could magnify response and power, representing a limitation in the model. For longer waves, this interaction will be less and this is consistent with results for $T_{\mathrm{p}}>1.4 \mathrm{~s}$, corresponding with wavelengths about $50 \%$ greater than the overall device dimension, being quite accurate. Reflections from the beach, of radiated as well as incident waves, in the wave basin could however also contribute to the discrepancy, representing a weakness in the experiments. An important point for this study is that power and response prediction is conservative and thus total power prediction, resulting in wave power transmission prediction for arrays, is also conservative. 
Mechanical power capture, often defined by capture width, has been investigated for many forms of wave energy converters (Falcão 2010; Babarit et al. 2012). It is well known that power radiated is similar to that converted and, for optimal conversion by a point absorber in regular waves at resonance, they are equal (Falnes 2002). There has been no evaluation of total power capture for more general forms of wave energy converter, to our knowledge. This is necessary for determining power capture and absorption from arrays of converters and down-wave impact on coastlines. Absorption also applies to floating wind farm arrays where additional power is absorbed due to drag, which can be substantial with damping plates on semi-sub types, as seen in Fig. 18.

Diffraction of waves by platforms will be small, as typical column widths are generally less than $20 \%$ of a wavelength, and thus in the inertia loading regime. However, radiated waves due to body motion will interact within an array of devices. Linear diffraction-radiation models may estimate this directly but it becomes very time-consuming for even small arrays, e.g. Sun et al. (2016). Göteman et al. (2015) showed that, for clusters of point absorbers in regular waves in an array (an array of arrays), the effect of radiated waves becomes negligible (wave amplitudes less than 5\% of ambient) at distances greater than about 5 wavelengths. The multi-float devices of interest here are hydrodynamically similar to clusters of point absorbers and the far field radiation effect may be expected to be reduced in irregular waves. Far field wave power is due to the onset or ambient power, less the effect of that absorbed by each device.

Determining radiated wave power experimentally is difficult and may be impossible, at least in multi-directional irregular waves, but it is straightforward in a linear model as it is simply due to the product of damping force and float velocity. This has been undertaken here for the multi-float M4 in 132 and 134 form, and for an idealised semi-sub wind platform. For wave energy converters, the total power absorption is at least twice mechanical power, and total power absorbed without PTO engaged is greater than with the PTO engaged. The split of radiated power between modes of heave, surge and individual float pitch shows that heave and surge dominate with heave greater but surge still significant. These results were with un-optimised linear mechanical damping. Importantly, it has been shown that control of PTO torque with auto-regression prediction can increase power capture by between $21 \%$ and $83 \%$ above optimum linear damping (Liao et al. 2020, 2021). The results estimated for power capture, mechanical and total, are thus an underestimate of what is possible.

There were some data available with directional waves, only with $\gamma=1$ for the $132 \mathrm{M} 4$, which show that PTO capture width is reduced by up to $50 \%$ for the larger $T_{\mathrm{p}}$, but this is where control was most effective in uni-directional waves. Clearly this is an area requiring further work. The total cap- ture width was more than twice the PTO capture width, up to four times.

For the semi-sub wind platform, the capture width was relatively small, around $10 \%$ of platform width and was only obtained for uni-directional waves. The objective for floating platforms supporting wind turbines is to make motion as small as possible, which is different from WEC platforms where the objective is to make power capture as large as possible, which generally occurs with large motions. Reducing motion of a wind platform by pumping water between floats is thus desirable and up to $40 \%$ reduction has been demonstrated by Stansby (2021), but this would reduce radiation damping further. Interestingly power capture by drag dominates for larger $T_{\mathrm{p}}$ and by radiation for lower $T_{\mathrm{p}}$, with the effect of surge the main contribution. Power absorption by drag, essentially from damping plates, is greater than that from wind turbine damping.

The far field wave propagation model for directional waves requires only the device capture width, spacing and the directional wave spread factor $s$. The simplified model is highly efficient. The capture width itself is dependent on platform configuration, $T_{\mathrm{p}}, \gamma$ and $s$, assuming linear waves. There will be additional nonlinear effects particularly in larger waves where, for example, drag and overtopping will generate additional losses. Incorporation of control will increase PTO capture and motion and hence radiation capture width. The values of total capture width normalised by platform width of 1 and 1.5 for the WEC and 0.1 for the semi-sub wind platform are considered representative. With a small WEC platform spacing of $600 \mathrm{~m}$ (full scale), wave power is reduced by almost 50\% across two long staggered rows. The reduction in wave power by a wind farm is quite small, less than 3\%, but could be useful. Experimental data for comparison would be of course be desirable.

The high absorption by multi-float WECs does suggest that rows would be effective for coastal protection. Since considerable funds are invested to protect vulnerable, but high value, coastlines the combination of WECs for power generation and coastal protection is complementary. Reducing wave propagation through wind farms is also beneficial, for structural and turbine loading and human safety, and rows of WECs around a wind farm would achieve this while also generating additional power.

\section{Conclusion}

The total wave power capture by a multi-float WEC due to radiation as well as mechanical PTO capture is estimated using linear diffraction-radiation modelling. The wave power absorption for a semi-sub wind platform due to drag and radiation is also estimated. Wave basin results for the multi-float WEC M4 in 132 form are compared with 
the modelling, including some results for directional spread waves. Mechanical power can be underestimated, by up to about $35 \%$ near maximum capture width, while accurate for longer waves. The reason for the underestimation has yet to be understood. For WECs total power, capture width is at least twice that due to PTO and radiation power is split mainly between heave and surge with heave generally greater. PTO was due to un-optimised linear dampers and torque control with auto-regressive forward prediction has been shown to increase power by between $21 \%$ and $83 \%$ above optimum linear damping. The capture widths are thus underestimates. Magnitudes for the 8-float 134 configuration with 4 PTOs are similar in terms of platform width which is $48 \%$ larger than for the 132 case. For the semi-sub wind platform, power absorption is due mainly to surge radiation and drag on the damping plates, with radiation dominating for lower periods and drag for larger.

An idealised far field wave power propagation model for arrays has been proposed for directional spread waves, where each device is regarded as small relative to spacing, providing a point sink for wave power, defined by capture width. Using representative capture widths, reduction of wave power for a floating wind array is quite small, less than $3 \%$ for a $10 \times 10$ array with $1 \mathrm{~km}$ spacing. For rows of WECs, power is reduced by up to $35 \%$ for 2 staggered rows with $1 \mathrm{~km}$ spacing and almost $50 \%$ with $600 \mathrm{~m}$ spacing. This does raise the potential for coastal protection and also protection of wind farms by rows of WECs around a wind farm.

Acknowledgements Support for experimental work through the EU Marinet 2 programme, project M4WW, and the Energy Sustainability Conayct-SENER fund provided by the Mexican government is gratefully acknowledged.

\section{Declarations}

Conflict of interest There are no conflicts of interest.

Open Access This article is licensed under a Creative Commons Attribution 4.0 International License, which permits use, sharing, adaptation, distribution and reproduction in any medium or format, as long as you give appropriate credit to the original author(s) and the source, provide a link to the Creative Commons licence, and indicate if changes were made. The images or other third party material in this article are included in the article's Creative Commons licence, unless indicated otherwise in a credit line to the material. If material is not included in the article's Creative Commons licence and your intended use is not permitted by statutory regulation or exceeds the permitted use, you will need to obtain permission directly from the copyright holder. To view a copy of this licence, visit http://creativecomm ons.org/licenses/by/4.0/. 


\section{Appendix}

See Tables 3, 4, 5 and 6.

Table 3 WEC mass of each component with centre of mass and inertia relative to O, shown in Fig. 2a

\begin{tabular}{|c|c|c|c|c|c|c|}
\hline & Mass (kg) & $x_{\mathrm{g}}(\mathrm{m})$ & $y_{\mathrm{g}}(\mathrm{m})$ & $z_{\mathrm{g}}(\mathrm{m})$ & $I_{x x}\left(\mathrm{kgm}^{2}\right)$ & $I_{y y}\left(\mathrm{kgm}^{2}\right)$ \\
\hline Bow float & 1.465 & -1.356 & 0 & -0.181 & 0.062 & 2.761 \\
\hline Bow/mid beams & 2.467 & -0.456 & 0 & -0.071 & 0.292 & 1.069 \\
\hline Mid-float port & 2.845 & -0.026 & 0.705 & -0.160 & 1.547 & 0.132 \\
\hline Ballast & 2.700 & -0.027 & 0.710 & -0.321 & 1.609 & 0.288 \\
\hline Mid-float centre & 2.845 & -0.026 & 0.005 & -0.160 & 0.131 & 0.132 \\
\hline Ballast & 2.700 & -0.027 & 0 & -0.321 & 0.286 & 0.288 \\
\hline Mid-float right & 2.845 & -0.026 & -0.694 & -0.160 & 1.505 & 0.132 \\
\hline Ballast & 2.700 & -0.027 & -0.699 & -0.321 & 1.609 & 0.288 \\
\hline Beams mid/stern & 0.525 & 0.328 & \pm 0.697 & 0.087 & 0.261 & 0.090 \\
\hline Stern float & 4.041 & 0.772 & \pm 0.700 & -0.204 & 2.248 & 2.680 \\
\hline Ballast & 13.000 & 0.772 & \pm 0.700 & -0.350 & 8.050 & 9.438 \\
\hline
\end{tabular}

Table 4 Wind turbine platform mass and inertia relative to $\mathrm{O}$, shown in Fig. 2b, of the floats and components

\begin{tabular}{lllllll}
\hline & Mass $(\mathrm{kg})$ & $x_{\mathrm{g}}(\mathrm{m})$ & $y_{\mathrm{g}}(\mathrm{m})$ & $z_{\mathrm{g}}(\mathrm{m})$ & $I_{x x}\left(\mathrm{kgm}^{2}\right)$ & $I_{y y}\left(\mathrm{kgm}^{2}\right)$ \\
\hline Bow mass & 2.60 & -1.356 & 0 & -0.257 & 0.217 & 5.035 \\
Bow ballast & 4.00 & -1.356 & 0 & -0.400 & 0.456 & 7.830 \\
Bow plate & 0.96 & -1.355 & 0 & -0.330 & 0.163 & 1.932 \\
Bow/mid beams & 2.467 & -0.456 & 0 & -0.071 & 0.292 & 1.069 \\
Mid-float left & 2.833 & -0.027 & -0.699 & -0.175 & 1.525 & 0.140 \\
Plate & 0.96 & -0.027 & -0.699 & -0.323 & 0.580 & 0.110 \\
Mid-float centre & 2.740 & -0.027 & 0 & -0.184 & 0.135 & 0.137 \\
Plate & 0.96 & -0.027 & 0 & -0.323 & 0.109 & 0.110 \\
Mid-float right & 2.833 & -0.027 & 0.699 & -0.175 & 1.525 & 0.149 \\
Plate & 0.96 & -0.027 & 0.699 & -0.323 & 0.580 & 0.110 \\
Turbine + support & 5.048 & -0.124 & 0.002 & 1.218 & 8.802 & 8.956 \\
\hline
\end{tabular}



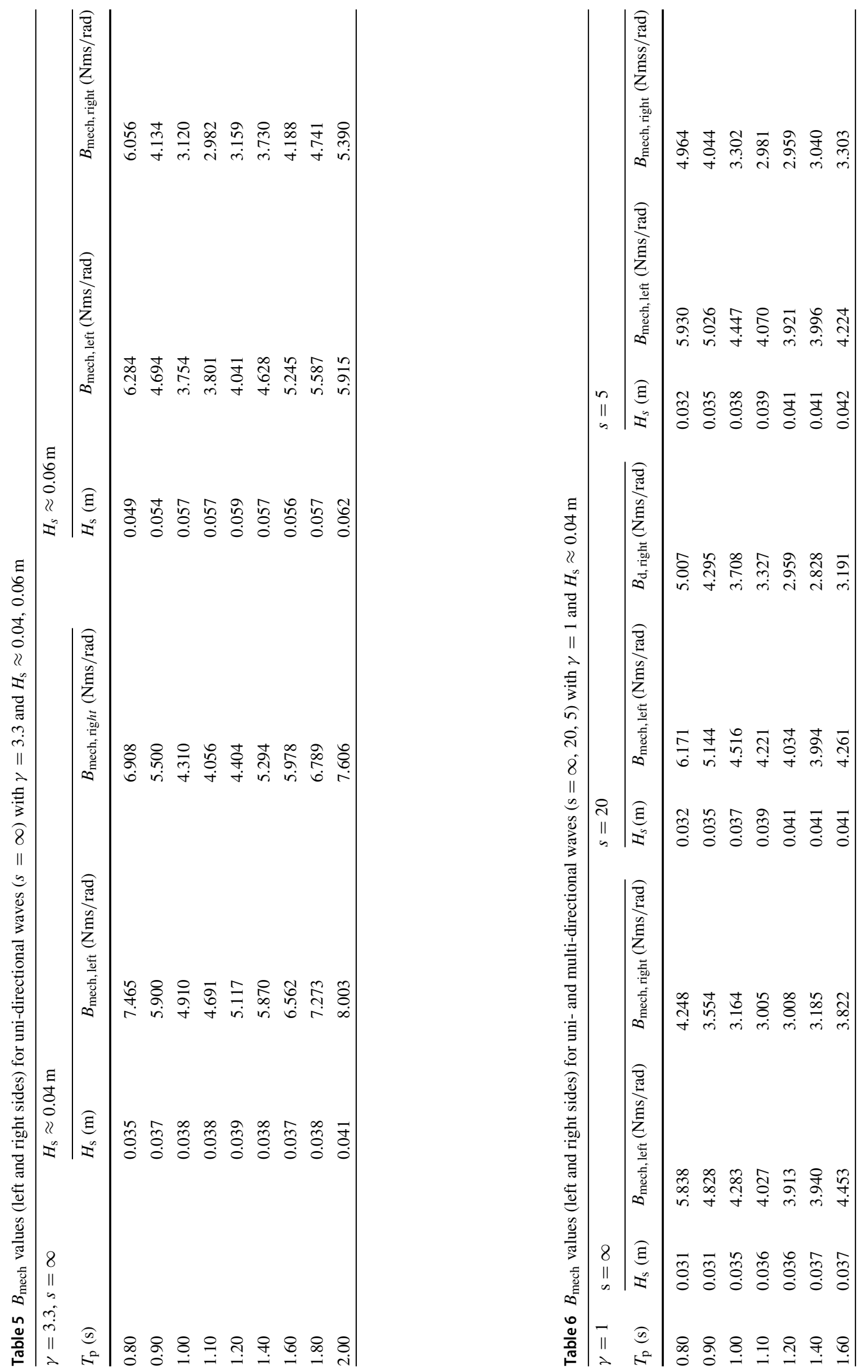


\section{References}

Abanades J, Greaves D, Iglesias G (2015) Coastal defence using wave farms: the role of farm-to-coast distance. Renew Energy 75:572-582

Apsley DD, Stansby PK (2020) Unsteady thrust on an oscillating wind turbine: comparison of blade-element momentum theory with actuator-line CFD. J Fluids Struct 98:103141

Babarit A, Hals J, Muliawan MJ, Kurniawan A, Moan T, Krokstad J (2012) Numerical benchmarking study of a selection of wave energy converters. Renew Energy 41:44-63

Bergillos RJ, Rodriguez-Delgado C, Iglesias G (2020) Ocean energy and coastal protection: a novel strategy for coastal management under climate change, part of the Springer briefs in energy book series. ISBN 978-3-030-31317-3

Carbon Trust (2015) Floating offshore wind: market and technology review. Report for the Scottish Government. https:// www.carbontrust.com/resources/floating-offshore-wind-markettechnology-review

Carpintero Moreno E, Stansby PK (2019) The 6-float wave energy converter M4: ocean basin tests giving capture width, response and energy yield for several sites. Renew Sustain Energy Rev 104:307-318

Chang G, Ruehl K, Jones CA, Roberts J, Chartrand C (2016) Numerical modeling of the effects of wave energy converter characteristics on nearshore wave conditions. Renew Energy 89:636-648

Cummins WE (1962) The impulse response function and ship motions. Schiffstechnik 9:101-109

de Falcão AFO (2010) Wave energy utilization: a review of the technologies. Renew Sustain Energy Rev 14:899-918

DNVGL (2019) DNVGL-RP-0286 coupled analysis of floating wind turbines. https://rules.dnv.com/docs/pdf/DNV/RP/2019-05/ DNVGL-RP-0286.pdf

Falnes J (2002) Ocean waves and oscillating systems. Cambridge University Press, Cambridge

Giorgi G, Ringwood JV (2018) Comparing nonlinear hydrodynamic forces in heaving point absorbers and oscillating wave surge converters. J Ocean Eng Mar Energy 4(1):25-35

Göteman M, Engström J, Eriksson M, Isberg J (2015) Fast modeling of large wave energy farms using interaction distance cut-off. Energies 8:13741-13757

Gu H, Stansby P, Stallard T, Carpintero Moreno E (2018) Drag, added mass and radiation damping of oscillating vertical cylindrical bodies in heave and surge in still water. J Fluids Struct 82(343-356):20

Jefferys E (1987) Directional seas should be ergodic. Appl Ocean Res 9(4):186-191

Jonkman J, Butterfield S, Musial W, Scott G (2009) Definition of a 5-MW reference wind turbine for offshore system development. Technical report NREL/TP-500-38060

Koo BJ, Goupee AJ, Kimball RW, Lambrakos KF (2014) Model tests for a floating wind turbine on three different floaters. J off Mech Arc Eng 136:020907

Latheef M, Swan C, Spinneken J (2017) A laboratory study of nonlinear changes in the directionality of extreme seas. Proc R Soc A 473:20160290. https://doi.org/10.1098/rspa.2016.0290

Lee CH, Newman JN (2013) WAMIT-user manual version 7.0. WAMIT Inc, Chestnut Hill, MA
Leimeister M, Kolios A, Collu M (2018) Critical review of floating support structures for offshore wind farm deployment. J Phys Conf Ser 1104:012007

Liao Z, Stansby P, Li G (2020) A generic linear non-causal optimal control framework integrated with wave excitation force prediction for multi-mode wave energy converters with application to M4. Appl Ocean Res 97:102056

Liao Z, Stansby P, Li G, Carpintero Moreno E (2021) High-capacity wave energy conversion by multi-floats, multi-PTO, control and prediction: generalised state-space modelling with linear optimal control and arbitrary headings. IEEE Trans Sustain Energy. https:// doi.org/10.1109/TSTE.2021.3082510

McNatt JC, Porter A, Chartrand C, Roberts J (2020) The performance of a spectral wave model at predicting wave farm impacts. Energies $13: 5728$

Mei CC (1999) The applied dynamics of ocean surface waves. World Scientific, Singapore

Rodriguez-Delgado C, Bergillos RJ, Iglesias G (2019) Dual wave farms for energy production and coastal protection under sea level rise. J Clean Prod 222:364-372

Ruehl K, Chartrand C, Porter A (2014) SNL-SWAN user's manual. Sandia National Laboratories, Albuquerque, NM, Bernalillo

Stansby PK (2021) Reduction of wave-induced pitch motion of a semisub wind platform by balancing heave excitation with pumping between floats. J Ocean Eng Mar Energy 7:157-172

Stansby PK, Carpintero Moreno E (2020a) Hydrodynamics of the multifloat wave energy converter M4 with slack moorings: time domain linear diffraction-radiation modelling with mean force and experimental comparison. Appl Ocean Res 97:102070

Stansby P, Carpintero Moreno E (2020b) Study of snap loads for idealized mooring configurations with a buoy, inextensible and elastic cable combinations for the multi-float M4 wave energy converter. Water 12(10):2818. Special issue on Numerical and experimental modelling of wave field variations around arrays of wave energy converters

Stansby P, Carpintero Moreno E, Stallard T (2017) Large capacity multifloat configurations for the wave energy converter M4 using a timedomain linear diffraction model. Appl Ocean Res 68:53-64

Stansby PK, Carpintero Moreno E, Apsley DD, Stallard TJ (2019) Slack-moored semi-submersible wind floater with damping plates in waves: linear diffraction modelling with mean forces and experiments. J Fluids Struct 90:410-431

Sun L, Stansby P, Zang J, Carpintero Moreno E, Taylor P (2016) Linear diffraction analysis and optimisation of the three-float multi-mode wave energy converter M4 in regular waves including small arrays. J Ocean Eng Mar Energy 2(4):429-438

Tao L, Thiagarajan K (2003) Low KC flow regimes of oscillating sharp edges. II. Hydrodynamic forces. Appl Ocean Res 25:53-62

Weller SD, Stallard TJ, Stansby PK (2010) Experimental measurements of irregular wave interaction factors in closely spaced arrays. IET Renew Power Gener 4(6):628-637. Selected from EWTEC conference 2009

Publisher's Note Springer Nature remains neutral with regard to jurisdictional claims in published maps and institutional affiliations. 